\title{
The Contribution of Black Carbon and Non-BC Absorbers to the Aerosol Absorption Coefficient in Nanjing, China
}

\author{
Ari Leskinen ${ }^{1,2 *}$, Antti Ruuskanen ${ }^{1}$, Pekka Kolmonen', Yu Zhao ${ }^{3}$, Die Fang ${ }^{3}$, Qingeng Wang ${ }^{3}$, \\ Cheng Gu${ }^{3}$, Jorma Jokiniemi ${ }^{4}$, Maija-Riitta Hirvonen ${ }^{4}$, Kari E.J. Lehtinen ${ }^{1,2}$, \\ Sami Romakkaniemi ${ }^{1}$, Mika Komppula ${ }^{1}$
}

\author{
${ }^{1}$ Finnish Meteorological Institute, Yliopistonranta 1 F, FI-70210 Kuopio, Finland \\ ${ }^{2}$ University of Eastern Finland, Department of Applied Physics, Yliopistonranta 1 F, FI-70210 Kuopio, Finland \\ ${ }^{3}$ Nanjing University, School of the Environment, 210023 Nanjing, China \\ ${ }^{4}$ University of Eastern Finland, Department of Environmental and Biological Sciences, Yliopistonranta 1 F, FI-70210 \\ Kuopio, Finland
}

\begin{abstract}
An aethalometer was employed in a 1-year campaign (November 2014-November 2015) in Nanjing, China, that aimed to estimate the contributions of black carbon (BC; annual average $\pm \mathrm{std}=4.0 \pm 3.3 \mu \mathrm{g} \mathrm{m}^{-3}$ ) and non-BC absorbers, such as brown carbon, to the aerosol absorption coefficient. We applied two methods: 1) the traditional calculation from the aethalometer data, assuming an absorption Ångström exponent (AAE) of unity for BC ("AE method"), which provided an overall average of $27.2 \%$ for the non-BC contribution, and 2) a recently developed method based on the wavelength dependence of AAE (the "WDA method"), which indicated the existence of non-BC absorbers in $25.3 \%$ of the samples on average. We utilized trajectory and source area analyses and, in agreement with the results from other studies in this region, verified biomass burning emission sources, mainly to the northwest of the measurement site.
\end{abstract}

Keywords: Aethalometer; Mie calculation; Trajectory analysis; Source area analysis.

\section{INTRODUCTION}

Particulate black carbon (BC) and non-BC absorbers have several effects on the environment and human health. For example, they affect the atmosphere's radiation balance both directly by absorbing incoming solar radiation (Bond et al., 2013) and indirectly and semi-directly by affecting the aerosols' cloud properties (Brown et al., 2018; Allen et al., 2019). On snow, BC decreases the snow albedo (Hadley and Kirchstetter, 2012), leading to warming of the snowy surfaces. When inhaled, the $\mathrm{BC}$ and non-BC absorbers may have adverse health effects (Janssen et al., 2012).

$\mathrm{BC}$, also called soot, originates from incomplete combustion and consists of carbonaceous components that strongly absorb radiation across the solar spectrum. The non-BC absorbers, in turn, include 1) dust, 2) organics that are "dark" in color (humic-like substances, HULIS) and 3) light-absorbing organic matter called "brown carbon" (BrC). Dust may be, e.g., blown by wind from the soil into the atmosphere, whereas

\footnotetext{
* Corresponding author.

Tel.: +358 505229148

E-mail address: Ari.Leskinen@fmi.fi
}

burning of biomass and biofuel is known to produce $\mathrm{BrC}$ in addition to $\mathrm{BC}$, and some light-absorbing organic compounds may be also generated in atmospheric transformation processes (Washenfelder et al., 2015). The BrC absorbs light preferentially at the upper end of ultraviolet region, a property that can be exploited in estimating the $\mathrm{BrC}$ contribution to the total light absorption of aerosol particles. The optical properties of $\mathrm{BC}$ and non-BC absorbers may also depend on their mixing state. For example, a layer of non$\mathrm{BC}$ compounds on $\mathrm{BC}$ particles may enhance the absorption efficiency of the BC core (Cappa et al., 2012).

The contribution of non-BC absorbers has been studied traditionally by measuring the absorption coefficients at several wavelengths, ranging from the ultraviolet to near-infrared, mostly with an aethalometer (AE). However, aethalometer measurements are known to suffer from two major artifacts: the filter loading effect and multiple scattering effect. To minimize and take into account these artifacts, both the instrument and the analysis methods have been developed. The filter loading effect is known to depend on the wavelength used in the analysis (Weingartner et al., 2003; Virkkula et al., 2007; Virkkula et al., 2015), and accurate compensation methods are needed for spectral measurements and subsequent source apportionment of $\mathrm{BC}$ or non-BC absorbers. Correcting the filter loading effect is quite straightforward (Virkkula et 
al., 2007), and it has already been implemented in an aethalometer using a dual-spot technology (Drinovec et al., 2015). The multiple scattering correction, in turn, is more complicated, and several algorithms have been developed over time (e.g., Weingartner et al., 2003; Arnott et al., 2005; Schmid et al., 2006; Collaud Coen et al., 2010). Many of these algorithms utilize concurrent scattering coefficient measurements in the corrections. If the scattering coefficient cannot be measured concurrently, it can be estimated, for example, by using Mie calculations if particle size distribution, shape, and refractive index are measured or estimated.

A recently developed method, called the "wavelength dependence of absorption Ångström exponent" (WDA) method (Wang et al., 2016), combines multi-wavelength absorption measurements and theoretical Mie calculations for BC. A great advantage of the WDA method is that it requires only multi-wavelength aethalometer measurements but no concurrent scattering or extinction measurements. However, the WDA method can be only used for finding out whether the inspected particulate sample contains other absorbers than $\mathrm{BC}$ or not.

In this study, the AE and WDA methods were applied in estimating the contribution of $\mathrm{BC}$ and non-BC absorbers to the aerosol absorption coefficient during a 1-year-long measurement campaign in Nanjing, China, in the Yangtze River Delta (YRD) region. The YRD is one of the most heavily polluted region in China with intensive industry and fossil fuel sources as well as an important area of agriculture production with occasional open biomass burning events influencing the regional and local air quality (Yang and Zhao, 2019). We evaluated the non-BC contribution to aerosol absorption coefficient for the emissions from some of these sources by using air mass back trajectories and meteorological measurements.

\section{METHODS}

\section{Measurement Site and Campaign Period}

The measurements were carried out at the Xianlin Campus of Nanjing University on the rooftop of a five-floor building, at about $30 \mathrm{~m}$ above the ground level. The measurement site $\left(32.117^{\circ} \mathrm{N}, 118.954^{\circ} \mathrm{E}\right)$ is located approximately $20 \mathrm{~km}$ east of the city center of Nanjing, which is an industrial megacity in the YRD (Fig. 1). The surroundings of the measurement site can be regarded as a suburban environment with the university area, residential areas, and traffic routes. A nearby highway, $300 \mathrm{~m}$ to the west of the measurement site, is one major source for traffic-related emissions. During the measurement campaign period of 5 November 2014-2 November 2015, construction sites at the campus area may also have caused elevated particle concentrations, particularly in the coarse fraction.

\section{Meteorological Parameters}

We measured ambient temperature, relative humidity, pressure, wind speed and direction, and precipitation intensity with a Vaisala Model WXT520 weather station that was equipped with a radiation and rain shield for the humidity and temperature sensors. The meteorological data were averaged over 1-minute time resolution for further analysis.

\section{Sampling and Sample Dilution}

The measurement instruments (Table 1) were located in an air-conditioned container, except the weather station that was installed approximately $2 \mathrm{~m}$ above the container roof in order to avoid disturbances by the nearby objects. The

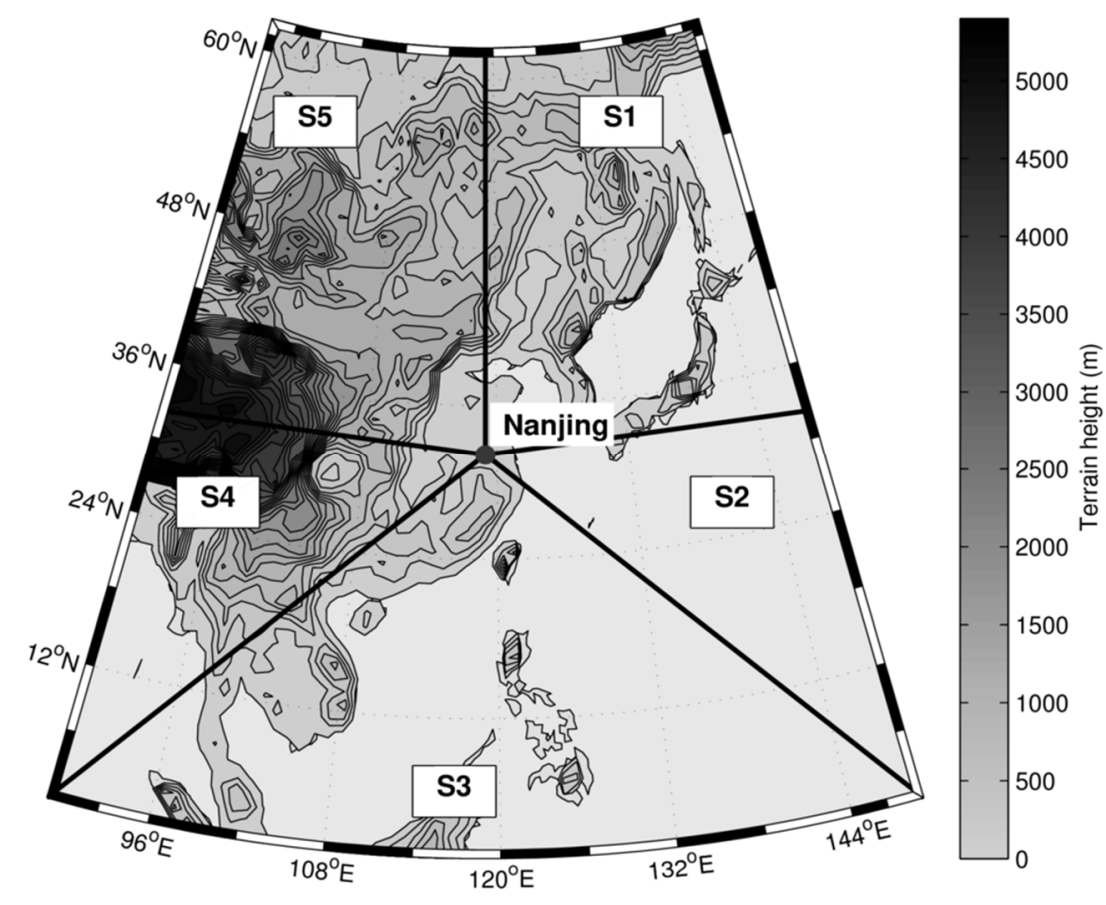

Fig. 1. The location of Nanjing, China (marked with the black dot), and the five selected sectors for air parcel backward trajectory analyses (separated by the black lines). 
Table 1. Instruments and their inlets for the measured properties.

\begin{tabular}{|c|c|c|}
\hline Measured property & Instrument & Inlet \\
\hline Aerosol light absorption & Aethalometer (Model AE-31; Magee Scientific) & $\mathrm{PM}_{6.5}$ \\
\hline Elemental carbon concentration & $\begin{array}{l}\text { Thermal-optical transmittance carbon analyzer (Model-4; } \\
\text { Sunset Lab) }\end{array}$ & $\mathrm{PM}_{2.5}$ \\
\hline Particulate mass concentration & $\begin{array}{l}\text { Tapered element oscillating microbalance (Model 1405D-BEF; } \\
\text { Thermo-Fisher Scientific) }\end{array}$ & $\mathrm{PM}_{2.5}$ and $\mathrm{PM}_{10}$ \\
\hline Aerosol particle size distribution & $\begin{array}{l}\text { NanoScan mobility particle sizer (Model 3910; TSI Inc.) and } \\
\text { optical particle sizer (Model 3330; TSI Inc.) }\end{array}$ & $\mathrm{PM}_{6.5}$ \\
\hline
\end{tabular}

sampling line for the instruments was a vertical stainless steel tube with a $10-\mathrm{mm}$ outer diameter through the roof of the container, and its inlet was covered with a rain shield. Inside the container the sampling line was thermally insulated in order to prevent condensation in the sampling line. Near the instruments, the sample line was divided for the measurement instruments. The calculated overall cut-off diameter (diameter with $50 \%$ collection efficiency for the sampling system; Fig. S1), considering diffusional, settling, and inertial losses in the inlet and sampling lines, was $6.5 \mu \mathrm{m}$ (called " $\mathrm{PM}_{6.5}$ inlet"). The estimated penetration efficiency for $10-\mu \mathrm{m}$ particles was $17 \%$. For some instruments, standard inlets for particulate matter less than $2.5 \mu \mathrm{m}$ in diameter $\left(\mathrm{PM}_{2.5}\right)$ and less than $10 \mu \mathrm{m}$ in diameter $\left(\mathrm{PM}_{10}\right)$ were used (Table 1$)$.

After 10 January 2015 the sample was diluted by using a porous tube diluter (constructed at the University of Eastern Finland) in order to lower the relative humidity in the sample and to reduce the risk of condensation in the sampling line. The dilution air flow was produced by a diaphragm pump following a high-efficiency particulate air (HEPA) filter (P/N 12144; Pall Corp.) at the flow rate of $3.0 \mathrm{~L} \mathrm{~min}^{-1}$. The total sampling rate of the instruments was $4.5 \mathrm{~L} \mathrm{~min}^{-1}$, so the sample flow rate from outside was $1.5 \mathrm{~L} \mathrm{~min}^{-1}$, and the concentration dropped in the diluter to $1 / 3$. The dilution air flow rate and its temperature and pressure were monitored continuously with a TSI Model 4140 mass flow meter and recorded for calculation of the exact dilution rate for every minute. The other flow rates were checked intermittently with the same mass flow meter.

\section{Equivalent Black Carbon Concentration and Absorption Coefficient}

Aerosol light absorption was measured with a Magee Scientific Model AE-31 aethalometer ("AE-31"). An aethalometer (Hansen et al., 1984) collects aerosol sample on a quartz fiber filter and measures the attenuation of a light beam transmitted through the sample on a filter material, whose clean part is used as a reference. An absorption coefficient $\left(b_{\text {abs }}\right)$, which is linearly dependent on the light attenuation, indicates how much light is absorbed per unit length (the unit of absorption coefficient is usually given as $\mathrm{Mm}^{-1}$ ). The AE-31 reports the measurement result as equivalent black carbon (EBC; Petzold et al., 2013) concentration at seven wavelengths $(370,470,520,590,660,880$, and $950 \mathrm{~nm})$. The EBC concentrations are obtained by dividing the absorption coefficient measured at each wavelength by a mass absorption efficiency (MAE), called also "mass absorption coefficient" (MAC). MAE is wavelength-dependent, and the
MAE values used in the AE-31, given by the instrument manufacturer, are derived from $14,625\left(\mathrm{~m}^{2} \mathrm{~g}^{-1} \mathrm{~nm}\right) \lambda^{-1}$, where $\lambda$ is the wavelength in $\mathrm{nm}$. By using the formula given by the manufacturer, the calculated values for the MAE are $39.5,31.1,28.1,24.8,22.2,16.6$, and $15.4 \mathrm{~m}^{2} \mathrm{~g}^{-1}$. The MAE could also be determined by dividing the measured absorption coefficient $\left(b_{\text {abs }}\right)$ by the elemental carbon (EC) concentration ([EC]) at the same location, simply by:

$\mathrm{MAE}=b_{\mathrm{abs}} /[\mathrm{EC}]$

The absorption coefficient at each of the AE-31 wavelengths was calculated by multiplying the corresponding EBC concentrations with the MAE. The aethalometer inlet flow rate was $5.9 \mathrm{~L} \mathrm{~min}^{-1}$ and $2.8 \mathrm{~L} \mathrm{~min}^{-1}$ before and after installing the dilution system, respectively, and the lowest possible data collection interval of 2 minutes.

In this study the EC concentration in $\mathrm{PM}_{2.5}$ was sampled and measured by a semi-continuous carbon analyzer (Model-4; Sunset Lab, USA) that applies the thermal-optical transmittance (TOT) method and uses a modified protocol of the National Institute of Occupational Safety and Health (NIOSH 5040) as its default protocol. The $\mathrm{PM}_{2.5}$ and $\mathrm{PM}_{10}$ concentrations, in turn, were measured with a tapered element oscillating microbalance (TEOM; Model 1405D-BEF, Thermo-Fisher Scientific Inc., USA).

\section{Aerosol Particle Size Distribution}

The aerosol particle size distribution was measured with a TSI NanoScan scanning mobility particle sizer (SMPS) Model 3910 and a TSI optical particle sizer (OPS) Model 3330. The SMPS measures particles with their diameters in the size range of $10-420 \mathrm{~nm}$ in 13 size bins, while the OPS measures particles with their diameters in the size range of $0.3-10 \mu \mathrm{m}$ in 16 size bins. The data from these two instruments were combined when applicable.

\section{Absorption Coefficient and Absorption Angström Exponent}

The absorption coefficient for each measured wavelength, $B_{\text {aeth }}(\lambda)$, was calculated by using the equation:

$\mathrm{B}_{\mathrm{aeth}}(\lambda)=\left(14,625 \lambda^{-1}\right) \times[\operatorname{EBC}(\lambda)]$

where the constant 14,625 is given by the manufacturer for "Magee BC" calibration, $\lambda$ is the wavelength $(\mathrm{nm})$, and $[\operatorname{EBC}(\lambda)]$ is the black carbon concentration $\left(\mathrm{ng} \mathrm{m}^{-3}\right)$ measured and reported by the aethalometer at that wavelength. The 
term $\left(14,625 \lambda^{-1}\right)$ is the MAE $\left(\mathrm{m}^{2} \mathrm{~g}^{-1}\right)$. By using appropriate unit conversions, the unit of $\mathrm{B}_{\text {aeth }}(\lambda)$ is $\mathrm{m}^{-1}$, but usually, as also in this study, $\mathrm{Mm}^{-1}$ is used as the unit for the absorption coefficient.

When there is a need to interpolate or extrapolate absorption coefficients at other wavelengths than at those with measurements, one can do this by using the absorption Angström exponent (AAE). The AAE for the absorption

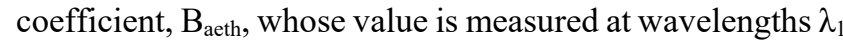
and $\lambda_{2}$, is defined as:

$\mathrm{AAE}_{\lambda 1-\lambda 2}=-\left[\log \left(\mathrm{B}_{\text {aeth, } \lambda 1} / \mathrm{B}_{\text {aeth }, \lambda 2}\right) / \log \left(\lambda_{1} / \lambda_{2}\right)\right]$

For example, if the absorption coefficient has been measured at 590 and $660 \mathrm{~nm}$, the absorption coefficient at wavelength $637 \mathrm{~nm}$ is:

$\mathrm{B}_{\text {aeth, } 637 \mathrm{~nm}}=\log \left(\mathrm{B}_{\text {aeth, } 590 \mathrm{~nm}} / \mathrm{B}_{\text {aeth, } 660 \mathrm{~nm}}\right) / \log (590 / 660) \times$ $\log (590 / 637)$

\section{Aethalometer Corrections}

The aethalometer is known to suffer from artifacts due to its filter-based measurement principle. Firstly, the dependence of the absorption coefficient on the light attenuation becomes non-linear with increasing aerosol mass on the filter tape, a so-called "filter loading" or "shadowing" effect. Secondly, multiple scattering from the aerosol particles on the filter and from the filter material increases the optical path of light, and the attenuation caused by the multiple scattering is misinterpreted as an attenuation caused by absorption. The corrected absorption coefficient, $\mathrm{B}_{\mathrm{abs}}$, can be calculated from:

$\mathrm{B}_{\mathrm{abs}}=\mathrm{B}_{\mathrm{aeth}} /\left(\mathrm{C}_{\mathrm{ref}} \times \mathrm{R}\right)$

where $\mathrm{B}_{\text {aeth }}$ is the absorption coefficient calculated from Eq. (2), $\mathrm{C}_{\text {ref }}$ is a correction coefficient for the multiple scattering effect and $\mathrm{R}$ is a correction coefficient for the filter loading effect. Both coefficients are wavelength-dependent.

In this work we used the Virkkula correction for the filter loading effect (Virkkula et al., 2007; Virkkula et al., 2015) with the assumption that the average of the last three values measured on a filter spot on the filter tape and the average of the first three values measured on the following filter spot are equal and that the correct value is the one measured after the filter change. It must be noted that this correction is used for filter loading effect only and it does not take the light scattering from the particles or the filter tape into account.

We performed similar validation as Drinovec et al. (2015) for the uncorrected and Virkkula-corrected data, averaged over the whole measurement period, and found that the correction removes the dependence of $\mathrm{BC}$ concentration on attenuation almost completely (Fig. S2(a)). This indicates good validity of the correction method for the $\mathrm{BC}$ data measured at 880-nm wavelength, particularly for the attenuation range of 5-55 with high enough observation frequency (Fig. S2(b)).

According to the recommendations by Collaud Coen et al. (2010), knowing or estimating the multiple scattering effect is important, especially at sites with high BC concentrations. In practice, the multiple scattering effect is estimated by calculating the coefficient $\mathrm{C}_{\text {ref }}$ in Eq. (5) by conducting parallel measurements of absorption coefficient at all desired wavelengths with a reference instrument that does not suffer from such a multiple scattering artifact. An ideal reference instrument would be one that retrieves the absorption coefficient for suspended particles, either directly or indirectly, by subtracting scattering coefficient from extinction coefficient. This is, however, often quite complicated, because many instruments used as a reference have their own artifacts, especially those using a filter-based measurement technique, or they measure the reference value only at one or a couple of wavelengths.

In this work we estimated the multiple scattering effect by calculating the $\mathrm{C}_{\text {ref }}$ for each wavelength the aethalometer measures by using the approach of Arnott et al. (2005). We used the equation

$\mathrm{B}_{\mathrm{abs}}=\left(\mathrm{B}_{\mathrm{aeth}}-\alpha \times \mathrm{B}_{\mathrm{sca}}\right) / \mathrm{M}$

derived from Eq. (27) in Arnott et al. (2005) by omitting the square root term describing the filter loading effect, instead of which we used the Virkkula correction. We adopted the coefficients $\alpha$ and $\mathrm{M}$ in Eq. (6) from Arnott et al. (2005). The $B_{\text {sca }}$ in Eq. (6) is the scattering coefficient measured concurrently with the aethalometer measurements.

Since we did not have concurrent scattering coefficient measurements, we calculated the scattering coefficients at each wavelength by applying Mie theory for the measured aerosol size distributions and by using the MatScat package for MATLAB (Schäfer, 2011; Schäfer et al., 2012), whose implementation is based on the theory in Bohren and Huffman (1998). In the calculations we assumed spherical particles with a wavelength-independent refractive index of $1.5-0.02 j$. The real part is the same as the average of the real parts of the refractive indices for different types of ambient aerosols measured in Guangzhou, China (Zhang et al., 2016). The real and imaginary parts are close to the value of 1.48$0.01 j$ obtained from AERONET observations in Beijing, China, and Mie calculations for fine particles at $440 \mathrm{~nm}$ (Zhang et al., 2017). With this method we obtained longterm averages for the $\mathrm{C}_{\text {ref }}$ of $3.04,3.31,3.41,3.51,3.62$, 3.97 , and 4.04 for the wavelengths $370,470,520,590,660$, 880, and $950 \mathrm{~nm}$, respectively. By using Eq. (3) the $\mathrm{C}_{\mathrm{ref}}$ at $637 \mathrm{~nm}$ would be 3.52 . This is close to the reference value $\mathrm{C}_{\text {ref }}=3.48$ at $637 \mathrm{~nm}$ in Xianghe, China, approximately 900 $\mathrm{km}$ north of Nanjing, determined by Ran et al. (2016), by using a Multi-Angle Absorption Photometer (MAAP; Petzold and Schönlinner, 2004; Petzold et al., 2005; Müller et al., 2011) as a reference instrument. A MAAP is a recognized reference instrument because it has an internal nephelometer to correct for the artifact caused by multiple scattering.

Kim et al. (2018) used a linear regression method and parallel measurements of aerosol absorption coefficient with an aethalometer and a photoacoustic soot spectrometer, for estimating the multiple scattering correction factor. Their estimated $\mathrm{C}_{\mathrm{ref}}$ values were $3.99,4.48$, and 5.46 at wavelengths of 405,532 , and $781 \mathrm{~nm}$, respectively. The $\mathrm{C}_{\text {ref }}$ values obtained by Kim et al. (2018) are up to 44\% higher than the values used in our study. 


\section{Estimating the Contribution of Non-BC Absorbers to the Absorption Coefficients}

In AE-31 the absorption coefficient measured at the wavelength of $880 \mathrm{~nm}$ can be attributed to black carbon if there is no dust. The absorption attributed to $\mathrm{BC}$ at lower wavelengths can be extrapolated from $880 \mathrm{~nm}$ by using an AAE of unity (e.g., Kirchstetter and Thatcher, 2012). The difference between the extrapolated and measured absorption coefficients at wavelengths below $880 \mathrm{~nm}$ can be regarded as the fraction caused by non-BC absorbers. It must be noted that the aerosol mixing type (internal or external) may have an effect on the interpretation of the BC-derived absorption. Furthermore, the AAE for externally and internally mixed $\mathrm{BC}$ may not actually be unity but may vary in as wide a range as $0.55-1.7$ (Lack and Langridge, 2013) because it depends on the particle size, shape, and chemical composition. Using a fixed value for AAE may lead to misinterpretations in estimating the absorption attributed to the non-BC absorbers. For example, Zhang et al. (2018a) used the AAE between 880 and $950 \mathrm{~nm}$ of 0.70 , after ruling out the negligible lensing effect by possible coating, for the extrapolation to the lower wavelengths, and observed more than $20 \%$ higher non-BC contributions than those estimated by assuming an AAE of unity. Liu et al. (2018) estimated a relatively sizeinsensitive AAE of 1.05 and 0.90 for fresh and aged BC particles, respectively, with a wavelength-independent refractive index. In measurements the mixing type problem can be partly overcome by using a drier or a denuder before the analyzer. In our measurement we did not use a denuder before the aethalometer but the sample was diluted with dry air (1/3 ambient sample, 2/3 dilution air), which may have enhanced evaporation of semi-volatile compounds on the $\mathrm{BC}$ particles before the instrument.

In this work we calculated the $\mathrm{BC}$ contribution at lower than 880-nm wavelengths by using the Ångström exponent law:

$\mathrm{B}_{\mathrm{abs}, \mathrm{BC}}(\lambda)=\mathrm{B}_{\mathrm{abs}}(\lambda=880 \mathrm{~nm}) \times(\lambda / 880)^{\mathrm{AAE}}$

where $\lambda(\mathrm{nm})$ is one of the lower wavelengths $(370,470$, $520,590$, or $660 \mathrm{~nm})$. We assumed the AAE of unity throughout the whole dataset, so the Eq. (7) reduces to:

$\mathrm{B}_{\mathrm{abs}, \mathrm{BC}}(\lambda)=\mathrm{B}_{\mathrm{abs}}(\lambda=880 \mathrm{~nm}) \times(\lambda / 880)$.

The estimated $\mathrm{BC}$ contribution to the $\mathrm{B}_{\mathrm{abs}}$ at each lower wavelength, $B_{a b s, B C}(\lambda)$, calculated from Eq. (8) was subtracted from the measured (and corrected) absorption coefficient at the same wavelength, $B_{a b s}(\lambda)$, in order to obtain the estimated contribution of non-BC absorbers to the $\mathrm{B}_{\mathrm{abs}}$ at those wavelengths, $B_{a b s, n o n-B C}(\lambda)$. The relative contribution of non$\mathrm{BC}$ absorbers to the absorption coefficient at each wavelength was calculated by using:

$\mathrm{f}_{\text {non-BC }}(\lambda)=B_{a b s, \text { non-BC }}(\lambda) / B_{a b s}(\lambda)$.

The non-BC contribution at the ultraviolet wavelength (370 nm in this case, calculated from Eq. (9)) provides a tool to estimate, for example, the existence of biomass-burning- originated aerosols

We also estimated the non-BC contribution by using the WDA method (Wang et al., 2016). This approach uses calculated AAE for two wavelength pairs from absorption measurements, the difference between these two AAE, and Mie calculations, for predicting the existence of non-BC absorbers in particles. In this work the AAE were calculated for the wavelength pairs of $370 / 880 \mathrm{~nm}, \mathrm{AAE}_{370 / 880}$, and $660 / 880 \mathrm{~nm}, \mathrm{AAE}_{660 / 880}$, and the WDA was calculated as:

$\mathrm{WDA}=\mathrm{AAE}_{370 / 880}-\mathrm{AAE}_{660 / 880}$

The calculated WDA values for each observation by using Eq. (10) were then compared with the WDA values calculated for an atmospherically relevant population of BC particles by using Mie theory. Fig. 4 illustrates this comparison: There is an additional contribution to the absorption coefficient by non-BC absorbers in the observations (marked with crosses) which lie above the shaded region, which, in turn, refers to absorption by BC only. For our Mie calculations we assumed spherical, coated particles and included lognormal particle size distributions with geometrical mean diameter (GMD) ranging from 20 to $300 \mathrm{~nm}$, geometrical standard deviation (GSD) ranging from 1.4 to 2.2 , and coating thickness ranging from $10 \%$ to $90 \%$ of the core diameter. We chose these values as typical for $\mathrm{BC}$ particles and to perform similar analysis as Wang et al. (2016) did. Accordingly, we used a refractive index of $1.95-0.79 j$ for the BC core (Bond and Bergström, 2006) and 1.55-0.001j for the coating material, as also Wang et al. (2016) did. It must be noted that these values are not necessarily constant over time but may vary based on varying physical properties and chemical composition of the particles. Saturno et al. (2018) found that changing the $\mathrm{BC}$ core size range from $100-275 \mathrm{~nm}$ to $80-275 \mathrm{~nm}$ and using a fixed refractive index of $1.55-0.001 j$ for the coating material may result in a relative overestimation of $18 \%$ in $\mathrm{BrC}$ contribution, whereas increasing the imaginary part of the refractive index of the coating material from 0.001 to 0.2 may result in a $56 \%$ relative overestimation in $\mathrm{BrC}$ contribution. Liu et al. (2018) found that variation in the BC refractive index (the real part in the range of 1.6-2.0 and imaginary part in the range of $0.4-1.0$ in their study) is the most significant challenge in determining the $\mathrm{BC}$ AAE as the refractive index cannot be measured directly.

The main advantages of the WDA method, compared to $\mathrm{AE}$ analysis, are that it does not require concurrent measurement of scattering or extinction coefficient, which reduces the number of instruments needed at the measurement site, and that it does not rely on any fixed assumption concerning the absorption Ångström exponent for BC (fixed at unity in most $\mathrm{AE}$ analyses) when estimating the non-BC contribution but rather relies on the atmospherically relevant range of $\mathrm{BC}$ properties. Furthermore, it does not require corrections due to wavelength-independent artifacts. However, aethalometer data must be corrected for the filter loading artifacts before using the WDA method in order to avoid misinterpretation due to the wavelength dependency of the filter loading effect (Virkkula et al., 2007, 2015).

It must be noted that one cannot compare directly the 
non-BC absorber contribution to the absorption coefficient obtained from the $\mathrm{AE}$ analysis to the fraction of samples containing non-BC absorbers obtained from the WDA analysis because of the different nature of these two approaches. However, these two methods can be applied in parallel for the same dataset. The WDA analysis indicates, for example, the frequency of occurrence of episodes with particles containing also non-BC absorbers in addition to $\mathrm{BC}$ only. The $\mathrm{AE}$ analysis can be applied in further analysis, reflecting the actual amount of non-BC absorbers in the particles. However, both methods can be applied in, e.g., source apportionment when the data are combined with meteorological measurements or back trajectory analysis.

\section{Trajectory Analysis}

The backward air parcel trajectories ending at the measurement site used in our source apportionment analysis were calculated by using the PC-based HYSPLIT model (Stein et al., 2015; Rolph et al., 2017). The trajectories were calculated for the preceding 5 days (120 hours) with a 1-hour time resolution. The output is the coordinates and the height above ground level of the air parcel at each hour. Other outputs used in this study were rainfall and terrain height.

The trajectories were classified according to their coordinates into five sectors, for which we assumed different types of aerosols (Fig. 1). The sectors were 1) "Yellow Sea" $\left.\left(0-90^{\circ}\right), 2\right)$ "East China Sea + Shanghai" (90-135 $)$, 3) "Southern China" (135-225 $)$, 4) "Southwestern China" $\left(225-270^{\circ}\right)$, and 5) "Northwestern China" (270-360 $)$. Aerosols from Sectors 1-3 are a mixture of marine and continental origin. Sector 1 includes parts of northern China, the Korean Peninsula, and Japan. Sector 2 is the most "marine" sector but the marine air masses spend also some time over the highly polluted YRD region, including the megacity of Shanghai. The air masses from Sector 3 are a mixture of marine aerosol and the southern megacities such as the Guangzhou-Shenzhen-Hong Kong region whereas the air masses from Sectors 4 and 5 are totally of continental origin. The division between southwestern and northwestern China was made by thinking of temperature differences: In the northern part houses are heated during wintertime whereas in the southern part heating is not as extensive.

\section{Source Area Analysis}

In order to determine $\mathrm{BC}$ and non-BC absorber sources outside of the Nanjing area, air mass back trajectories were utilized together with the $\mathrm{BC}$ measurements. The basic idea for this source area analysis has been introduced by Hyvärinen et al. (2011) and is described here briefly. The region of eastern China around Nanjing was divided into a $0.5 \times 0.5^{\circ}$ regular grid. 72-hour air mass back trajectories were computed using the HYSPLIT model. The trajectories were computed every 3 hours for the period of the $\mathrm{BC} /$ non$\mathrm{BC}$ measurements, leading to 7,614 trajectory- $\mathrm{BC} /$ non- $\mathrm{BC}$ measurement pairs. For each grid cell the number of "hits" from a trajectory corresponding to a $\mathrm{BC}$ measurement was recorded. This number represents the time that the air mass following a trajectory spends in a grid cell. When this procedure was repeated for each trajectory- $\mathrm{BC} /$ non-BC pair, an observation matrix, A, was constructed. The vector of measurements was denoted by $b$ and the source $\mathrm{BC} /$ non-BC concentration vector was denoted by $x$. Now the source determination problems can be formulated as the equation $b$ $=\mathrm{Ax}$, and the unknown source vectors can be solved simply as an inverse parameter estimation problem by $\mathrm{x}=\mathrm{A}^{-1} \mathrm{~b}$. It must be noted that Matrix A of the source area analysis is very rank-deficient implying that some sort of regularization method must be used. The chosen method in our analysis was the minimum norm Tikhonov regularization (Tarantola, 1987).

\section{RESULTS AND DISCUSSION}

\section{Meteorological Conditions}

The monthly averages of selected meteorological parameters and the cumulative rainfalls are given in Table 2 . The lowest and highest temperatures, $-3.1^{\circ} \mathrm{C}$ and $37.3^{\circ} \mathrm{C}$, were observed on 9 February 2015 and 4 August 2015, respectively. The humid summer with high relative humidity and rainfall and dry winter are typical near an east coast in a subtropic climate. This can also be seen in the monthly trajectory distribution (Fig. S3) with continental air masses in winter and maritime air masses in summer. The prevailing winds at the measurement site were from north and south (Fig. S4). The winds from the west at and in the vicinity of the

Table 2. Monthly averages \pm std of meteorological parameters. $\mathrm{T}=$ temperature, $\mathrm{RH}=$ relative humidity, $\mathrm{p}=$ pressure, $\mathrm{ws}$ $=$ wind speed.

\begin{tabular}{llllll}
\hline Month & $\mathrm{T}\left({ }^{\circ} \mathrm{C}\right)$ & $\mathrm{RH}(\%)$ & $\mathrm{p}(\mathrm{mbar})$ & $\mathrm{ws}\left(\mathrm{m} \mathrm{s}^{-1}\right)$ & Rainfall $(\mathrm{mm})$ \\
\hline November 2014 & $12.9 \pm 2.9$ & $65.0 \pm 16.2$ & $1018.5 \pm 4.3$ & $2.0 \pm 1.1$ & 48.2 \\
December 2014 & $5.4 \pm 3.1$ & $49.1 \pm 15.8$ & $1024.0 \pm 4.1$ & $2.1 \pm 1.2$ & 2.3 \\
January 2015 & $5.8 \pm 3.8$ & $57.6 \pm 17.8$ & $1022.1 \pm 5.8$ & $2.0 \pm 1.0$ & 11.3 \\
February 2015 & $5.0 \pm 3.9$ & $50.6 \pm 18.1$ & $1023.1 \pm 6.5$ & $1.8 \pm 1.0$ & 0.2 \\
March 2015 & $11.3 \pm 5.7$ & $64.5 \pm 16.1$ & $1016.0 \pm 6.3$ & $2.2 \pm 0.9$ & 47.4 \\
April 2015 & $16.2 \pm 5.9$ & $56.7 \pm 19.2$ & $1011.2 \pm 7.1$ & $2.4 \pm 1.4$ & 101.6 \\
May 2015 & $22.0 \pm 3.5$ & $58.4 \pm 17.4$ & $1005.0 \pm 3.6$ & $2.3 \pm 1.1$ & 57.8 \\
June 2015 & $24.8 \pm 3.1$ & $70.8 \pm 16.3$ & $1000.3 \pm 2.9$ & $2.2 \pm 0.9$ & 561.0 \\
July 2015 & $26.3 \pm 4.0$ & $69.0 \pm 13.3$ & $1000.6 \pm 4.0$ & $2.2 \pm 1.2$ & 79.5 \\
August 2015 & $27.7 \pm 3.4$ & $66.8 \pm 13.7$ & $1002.5 \pm 2.1$ & $2.1 \pm 1.1$ & 267.6 \\
September 2015 & $23.5 \pm 2.5$ & $65.8 \pm 13.6$ & $1009.3 \pm 3.5$ & $1.9 \pm 1.0$ & 76.3 \\
October 2015 & $19.1 \pm 3.5$ & $60.1 \pm 16.0$ & $1015.6 \pm 3.9$ & $1.9 \pm 1.1$ & 19.2 \\
\hline
\end{tabular}


measurement site have been sparse (Ding et al., 2013; Chen et al., 2017).

\section{Equivalent Black Carbon Concentration}

The annual average \pm std of the measured EBC concentration at $880 \mathrm{~nm}$ was $4.0 \pm 3.3 \mu \mathrm{g} \mathrm{m}^{-3}$ with a maximum of $50.9 \mu \mathrm{g} \mathrm{m}^{-3}$ (Fig. S5(a)). The annual average of the EBC concentration is $2-5 \%$ lower than the values of $4.1 \pm 2.8 \mu \mathrm{g} \mathrm{m}^{-3}$ and $4.2 \pm 2.6 \mu \mathrm{g} \mathrm{m}^{-3}$ measured at the nearby SORPES station during July 2013-May 2015 (Shen et al., 2018; re-calculated from the 2-year average of absorption coefficient of $16 \mathrm{Mm}^{-1}$, by using Eqs. (2) and (5) and the reported $\mathrm{C}_{\text {ref }}$ value of 4.26) and in Nanjing city center during the year 2012 (Zhuang et al., 2014), respectively. Zhuang et al. (2017) reported an average absorption coefficient of $29.615 \mathrm{Mm}^{-1}$ at $550 \mathrm{~nm}$ in the Nanjing city center for the time period March 2014-February 2016. By using the given statistics and Eqs. (2), (3) and (5), the average EBC concentrations at $660 \mathrm{~nm}$ and $880 \mathrm{~nm}$ are estimated to be $4.0 \mu \mathrm{g} \mathrm{m}^{-3}$ and $3.8 \mu \mathrm{g} \mathrm{m}^{-3}$, respectively. Our values, $4.0 \mu \mathrm{g} \mathrm{m}^{-3}$ at both $660 \mathrm{~nm}$ and $880 \mathrm{~nm}$, are within $5 \%$ of those calculated from the Zhuang et al. (2017) data. The differences in the EBC concentrations measured at our site, the SORPES station, and Nanjing city center may arise from bigger $\mathrm{BC}$ emissions in the city center, or a decreasing trend in the annual average of $\mathrm{BC}$ concentrations, which can be deduced from the EBC concentrations of $4.2 \mu \mathrm{g} \mathrm{m}^{-3}$ for 2012 (measured at $880 \mathrm{~nm}$ by Zhuang et al., 2014) and $3.8 \mu \mathrm{g} \mathrm{m}^{-3}$ for 2014-2016 (estimated at $880 \mathrm{~nm}$ from Zhuang et al., 2017) in Nanjing city center. Furthermore, differences in the averaging periods, experimental setups, and measurement errors, as well as data processing procedures may complicate the comparison.

The seasonal averages \pm std of EBC concentrations at $880 \mathrm{~nm}$ were $3.5 \pm 3.6 \mu \mathrm{g} \mathrm{m}^{-3}$ in the spring (March-May), $4.0 \pm 3.1 \mu \mathrm{g} \mathrm{m}^{-3}$ in the summer (June-August), $3.3 \pm$ $2.3 \mu \mathrm{g} \mathrm{m}^{-3}$ in the autumn (September-November), and $5.5 \pm$ $3.8 \mu \mathrm{g} \mathrm{m}^{-3}$ in the winter (December-February). It must be noted that the gaps in the aethalometer data before midJanuary 2015 may have an influence on the results. We estimated this influence by calculating the averages of $\mathrm{PM}_{10}$ and $\mathrm{PM}_{2.5}$ that had far less gaps. During this period the averages for $\mathrm{PM}_{10}$ were 101.8, 103.6, and $100.6 \mu \mathrm{g} \mathrm{m}^{-3}$ for the whole dataset, for the hours when AE data was available, and for the hours when $\mathrm{AE}$ data was unavailable, respectively. For $\mathrm{PM}_{2.5}$ the corresponding values were 58.2, 59.0, and $57.7 \mu \mathrm{g} \mathrm{m}^{-3}$, respectively. Based on these calculations, we may have overestimated the monthly averages of EBC concentrations but by no more than $3 \%$.

The EBC concentration varied also diurnally (Fig. S6).
The diurnal variation pattern was similar for each season, showing the lowest concentrations at 1-2 p.m. when the mixing depth is at its highest, and highest concentrations during the night. At around 7 a.m., a small increase in the EBC concentration was seen, probably due to morning traffic and its emissions. The pattern was similar to those measured at the same site (Chen et al., 2017), at the nearby SORPES station (Shen et al., 2018), and in the Nanjing city center (Zhuang et al., 2014).

With the measured $\mathrm{PM}_{2.5}$ and $\mathrm{PM}_{10}$ hourly averages (Fig. S5(b)), the annual average \pm std of the $\mathrm{EBC} / \mathrm{PM}_{2.5}$ and $\mathrm{EBC} / \mathrm{PM}_{10}$ were $0.14 \pm 1.36$ and $0.14 \pm 2.9$, respectively. The high standard deviation arises from the fact that the calculated fractions become inaccurate and large with low PM concentrations. The $1^{\text {st }}, 50^{\text {th }}$ (median), and $99^{\text {th }}$ percentiles for the $\mathrm{EBC} / \mathrm{PM}_{2.5}$ and $\mathrm{EBC} / \mathrm{PM}_{10}$ fractions were 0.015 , 0.073 , and 0.49 , and $0.009,0.046$, and 0.45 , respectively.

The median EBC concentration in the air masses from Sectors 1-5 ranged from 2.7 to $4.6 \mu \mathrm{g} \mathrm{m}^{-3}$ (Table 3). Overall, the highest $\mathrm{EBC}$ concentrations were observed in the air masses from the southern sector (Sector 3) and with southerly winds, except during the autumn and winter (Fig. S7). The average EBC concentration in Sector 3 may be, however, biased by the fact that it was the main sector more seldom than the northern sectors, Sectors 1 and 5 (number of observations $=3727,693,713,354$, and 3153 for Sectors $1-$ 5 , respectively), and mainly in summer (Figs. S3 and S15). Furthermore, in most cases there had been rain relatively close to the measurement site (Fig. S3), which means that the higher EBC concentration in the air masses from Sector 3 (Table 3) can be attributed to emission sources in the vicinity of the measurement site rather than to long-range transported aerosol.

\section{Aethalometer Equivalent Black Carbon and Thermal- optical Elemental Carbon Comparison}

The hourly average EC concentration had an annual average \pm std of $3.3 \pm 2.0 \mu \mathrm{g} \mathrm{m}^{-3}$ and a maximum of $37.6 \mu \mathrm{g} \mathrm{m}^{-3}$ (Fig. S8(a)). This is continuation for the earlier EC measurements at the same site by Chen et al. (2017), who observed an annual average EC concentration of $3.2 \mu \mathrm{g} \mathrm{m}^{-3}$ for the year 2014. By calculating the monthly averages for our EC data and combining them with those calculated by Chen et al. (2017) we can see that the EC concentration decreased at an average rate of $0.078 \mu \mathrm{g} \mathrm{m}^{-3}$ per month between June 2013 and October 2015 (Fig. S9). This may be due to an overall improvement of regional air quality thanks to reduction of emissions, or local actions taken in order to improve air quality. For example, actions were taken to reduce pollutant emissions before and during the Nanjing

Table 3. Medians of several parameters from different trajectory analysis sectors.

\begin{tabular}{llllll}
\hline & Sector 1 & Sector 2 & Sector 3 & Sector 4 & Sector 5 \\
\hline EBC conc $\left(\mu \mathrm{g} \mathrm{m}^{-3}\right)$ & 2.68 & 2.69 & 4.58 & 3.92 & 3.25 \\
EC conc $\left(\mu \mathrm{g} \mathrm{m}^{-3}\right)$ & 2.56 & 2.67 & 3.17 & 3.51 & 3.11 \\
MAE & 4.41 & 4.71 & 6.16 & 4.98 & 4.35 \\
non-BC fraction AE (\%) & 26.3 & 24.5 & 25.8 & 28.1 & 29.5 \\
non-BC contribution WDA (\%) & 22.2 & 30.6 & 21.2 & 30.5 & 21.3 \\
\hline
\end{tabular}


2014 Youth Olympic Games (YOG) that took place between 16-28 August 2014. The effect of the emission reductions can be seen as a lower EC concentration during the summer of 2014 compared to that during the summer of 2015 (Fig. S9). Also reduction in other air pollution components during the YOG have been reported (Miettinen et al., 2019; Zhao et al., 2017a; Zhou et al., 2017).

The seasonal averages of the EC concentration were 2.8 $\pm 1.3 \mu \mathrm{g} \mathrm{m}^{-3}$ (spring), $2.8 \pm 1.9 \mu \mathrm{g} \mathrm{m}^{-3}$ (summer), $3.2 \pm$ $1.8 \mu \mathrm{g} \mathrm{m}^{-3}$ (autumn), and $4.5 \pm 2.4 \mu \mathrm{g} \mathrm{m}^{-3}$ (winter). Chen et al. (2017) reported seasonal average EC concentrations of $3.41,2.51,2.54$, and $4.37 \mu \mathrm{g} \mathrm{m}^{-3}$ for spring 2014 , summer 2014, autumn 2014, and winter 2014-2015, respectively. The EBC and EC concentrations in the winter were 1.4-1.6 times that during the other seasons, which can be at least partly explained by an increased need of energy for heating of housings during the cold seasons, which increases emissions from power plants, and partly by the 1.2-fold average of mixing depth over the other seasons $(462 \mathrm{~m}$ ) than over winter (391 m), which causes the emissions to accumulate in a lesser volume in winter. It must be noted that there were gaps in our aethalometer data due to instrument or data acquisition system malfunction, which may cause bias to the calculated averages, particularly for the summer values when a longer break in the valid data was experienced between 19-29 July 2015. However, we expect the calculated summertime average for the aethalometer data to represent well the summer average, because during this 10-day time period the average \pm std of EC concentration was $3.0 \pm$ $1.6 \mu \mathrm{g} \mathrm{m}^{-3}$ which is close to the average \pm std of the EC concentration of $2.8 \pm 1.9 \mu \mathrm{g} \mathrm{m}^{-3}$ for the whole summer. The $\mathrm{EC}$ concentrations were highest during winter and in the air masses from the southern sector (Fig. S10).

The hourly ratio of EBC to EC concentration had high variability (Figs. S8(b) and S11). The linear relationship is $[\mathrm{EBC}]=1.05[\mathrm{EC}]$ (Fig. S11). Zhao et al. (2017b) reported a linear relationship of $[\mathrm{BC}]=0.6812[\mathrm{EC}]+0.9683$ to the values measured in Nanjing city center in 2015. Zhi et al. (2014) observed a BC/EC ratio of 0.92 in Shanghai on clear weather, while during heavy haze days the ratio increased up to 1.9. Haze may also play a role in our observations in Nanjing. The differences in the EBC/EC ratios may arise from differences in the mixing state of particles, i.e., internal mixing of EC with other species. It is known that an organic coating may enhance light absorption into an aerosol particle (e.g., Bond et al., 2013), which increases the $\mathrm{EBC} / \mathrm{EC}$ ratio.

It must be noted that our estimation for the $\mathrm{EBC}$ in the $\mathrm{PM}_{2.5}$ fraction relies solely on the particulate masses in $\mathrm{PM}_{2.5}$ and in the fraction of larger than $2.5-\mu \mathrm{m}$ particles. $\mathrm{BC}$, however, resides in the smaller submicron size fraction, whereas the supermicrometer size fraction is dominated by dust (Clarke et al., 2004). Therefore, we conclude that our EBC mass concentrations can be safely used in comparison with the $\mathrm{PM}_{10}$ and $\mathrm{PM}_{2.5}$ mass concentrations, as well as in comparison with the EC concentration measured from the $\mathrm{PM}_{2.5}$ fraction, even though our sampling system had an estimated cut-off diameter of $6.5 \mu \mathrm{m}$. It must also be noted that the larger dust particles that are not removed by any precut instrument in our case, may scatter light effectively, which would cause enhanced scattering by the sample collected on the aethalometer filter, leading to an overestimation of absorption. In order to take this into account, we calculated the scattering by applying Mie theory to the measured size distributions.

By using Eq. (1) we obtained an average MAE of $5.3 \mathrm{~m}^{2} \mathrm{~g}^{-1}$ at $880 \mathrm{~nm}$. It must be noted that MAE is not constant over time (Fig. S8(c)). During our campaign the MAE varied between $0.98 \mathrm{~m}^{2} \mathrm{~g}^{-1}\left(1^{\text {st }}\right.$ percentile) and $19.9 \mathrm{~m}^{2} \mathrm{~g}^{-1}\left(99^{\text {th }}\right.$ percentile). Elevated MAE values were observed in winter with westerly winds and in summer with southerly winds (Fig. S12). The average MAE values for Sectors $1-5$ were $5.28,5.82,6.98,5.49$, and $4.84 \mathrm{~m}^{2} \mathrm{~g}^{-1}$, respectively. The $\mathrm{MAE}$ values are inversely proportional to the non- $\mathrm{BC}$ fraction obtained from the AE analysis (Table 3). Cheng et al. (2011) attributed a lower MAE value of EC to an increased impact of biomass burning aerosols. Correspondingly, the highest MAE values in Sector 3 in our study may be attributed to aerosols from nearby sources and a relatively fresh aerosol with a lower non-BC fraction.

Our observations are in conjunction with the fact that the MAE bound to $\mathrm{BC}$ only, $\mathrm{MAE}_{\mathrm{BC}}$, has been observed to vary between a range of 2-39 (Quinn and Bates, 2005; Cheng et al., 2011; Bond et al., 2013). The variation is at least partly connected to abundant organic carbon and organic-toelemental carbon ratio (OC/EC), particularly those in the secondary organic aerosol after atmospheric transformation, as was found, for example, by Cheng et al. (2011) in Beijing, China, and Zhang et al. (2018b) in Xi'an, China. The highest MAE values have been assigned to the internally mixed core-shell particle type or to elevated ambient relative humidity, as a coating on $\mathrm{BC}$ particles acts as a lens that may enhance absorption (Quinn and Bates, 2005; Bond et al., 2013; Ammerlaan et al., 2017).

\section{Contribution of Non-BC Absorbers to the Absorption Coefficients}

The annual averages \pm std of the absorption coefficients at 370,520 , and $880 \mathrm{~nm}$, for example, were $54 \pm 44,32 \pm$ 25 , and $17 \pm 14 \mathrm{Mm}^{-1}$, respectively, with a large variation (Fig. 2(a)). The averages are 38\%, 23\%, and 6\% higher than the values of $39 \pm 30,26 \pm 19$, and $16 \pm 11 \mathrm{Mm}^{-1}$ observed at the SORPES station during July 2013-May 2015 (Shen et $a l ., 2018)$. The differences may arise from the different time spans of the two datasets, although there is an overlap of seven months. The annual average \pm std of the absorption Angström exponent between $370 \mathrm{~nm}$ and $880 \mathrm{~nm}, \mathrm{AAE}_{370 / 880}$, was $1.05 \pm 0.32$. The $\mathrm{AAE}_{370 / 880}$ has maxima in the winter and in the summer (Fig. 2(b)). Ran et al. (2016) found a similar pattern (except for June) for the AAE in the North China Plain during April 2013-March 2015. Bukowiecki et al. (2019) linked an elevated AAE to high biomass burning periods in northern Southeast Asia.

The annual averages of the absorption coefficient and the non-BC attributed absorption at $370 \mathrm{~nm}$, calculated by using the AE method, were $54.0 \mathrm{Mm}^{-1}$ and $14.4 \mathrm{Mm}^{-1}$, respectively (Fig. 3), and the median and $99^{\text {th }}$ percentile of the relative contribution of the non-BC absorbers at $370 \mathrm{~nm}$ were $27.2 \%$ and $64.8 \%$, respectively. The relative non-BC contribution 

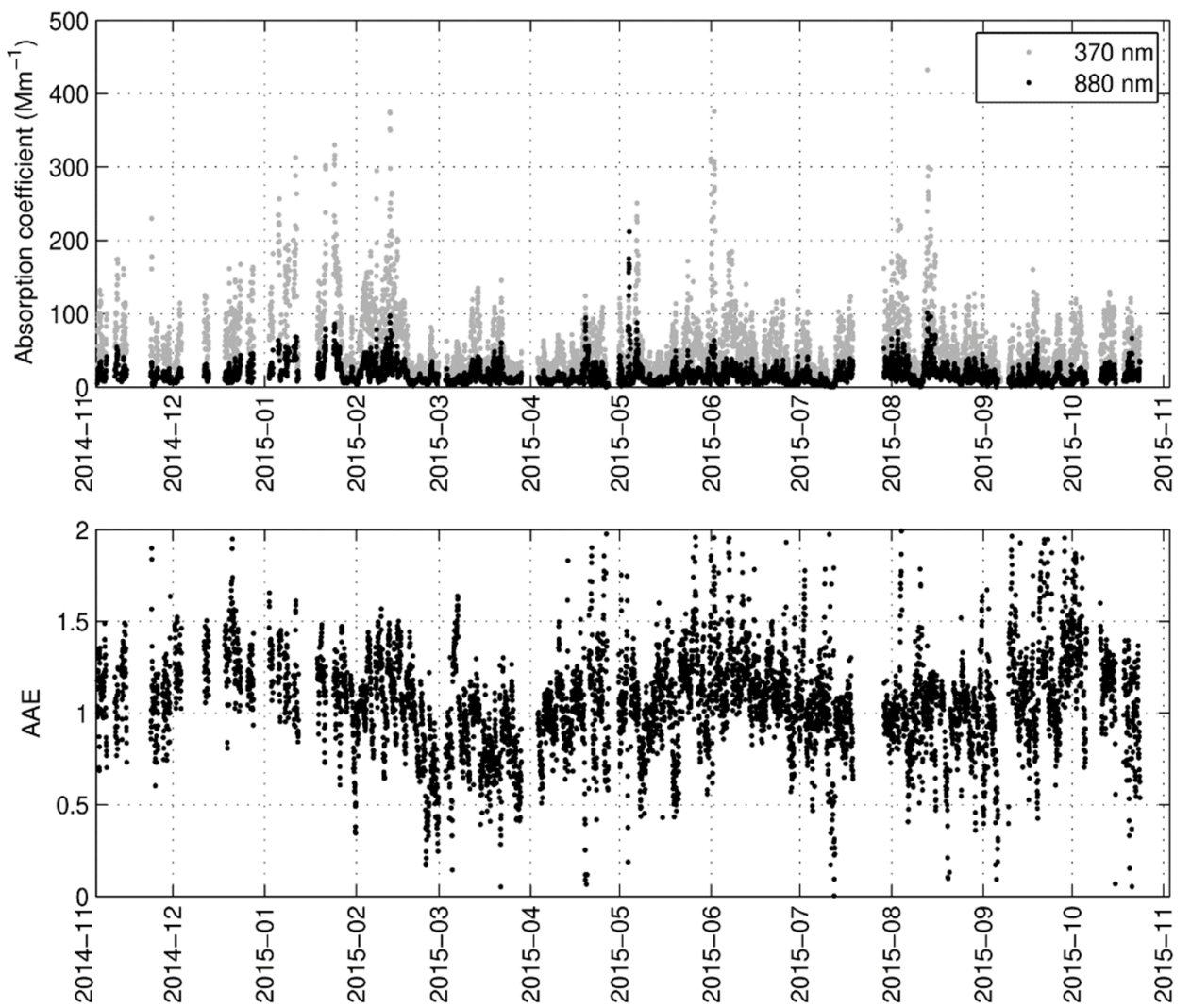

Fig. 2. A time series of (a) absorption coefficient at 370 (light gray) and $880 \mathrm{~nm}$ (black) and (b) the absorption Ångström exponent (AAE) between $370 \mathrm{~nm}$ and $880 \mathrm{~nm}$.

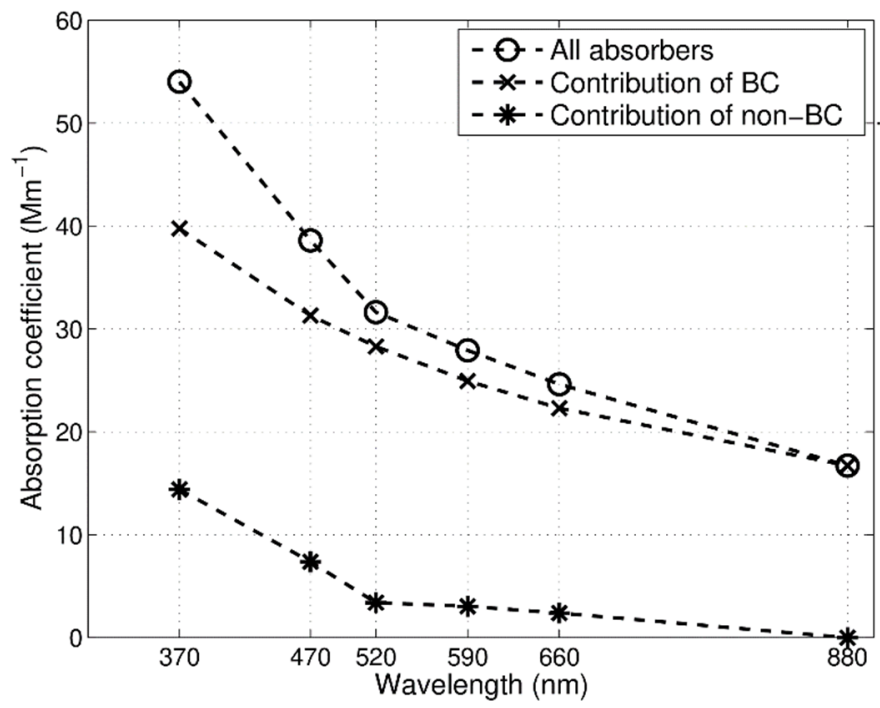

Fig. 3. Long-term average of absorption coefficient and the contributions of all, BC, and non-BC absorbers at each measured wavelength.

was highest in December and in June, and lowest in March (Fig. 5). The elevated non-BC contribution in December and June may also be attributed to open biomass burning during post-harvest seasons, typically taking place in May-June and October-November (Cheng et al., 2014). Ran et al. (2016) found a $33-40 \%$ BrC contribution during non-heating seasons, and up to $59 \%$ contribution during the heating season.
The elevated contribution of non-BC absorbers during the heating season may arise from higher organic emissions (Chen et al., 2017).

The WDA analysis showed that there were non-BC absorbers, on average, in $25.3 \%$ of the samples during the measurement period (Fig. 4). Also here, monthly variation was observed (Figs. 6 and S13), ranging from 8\% (January 


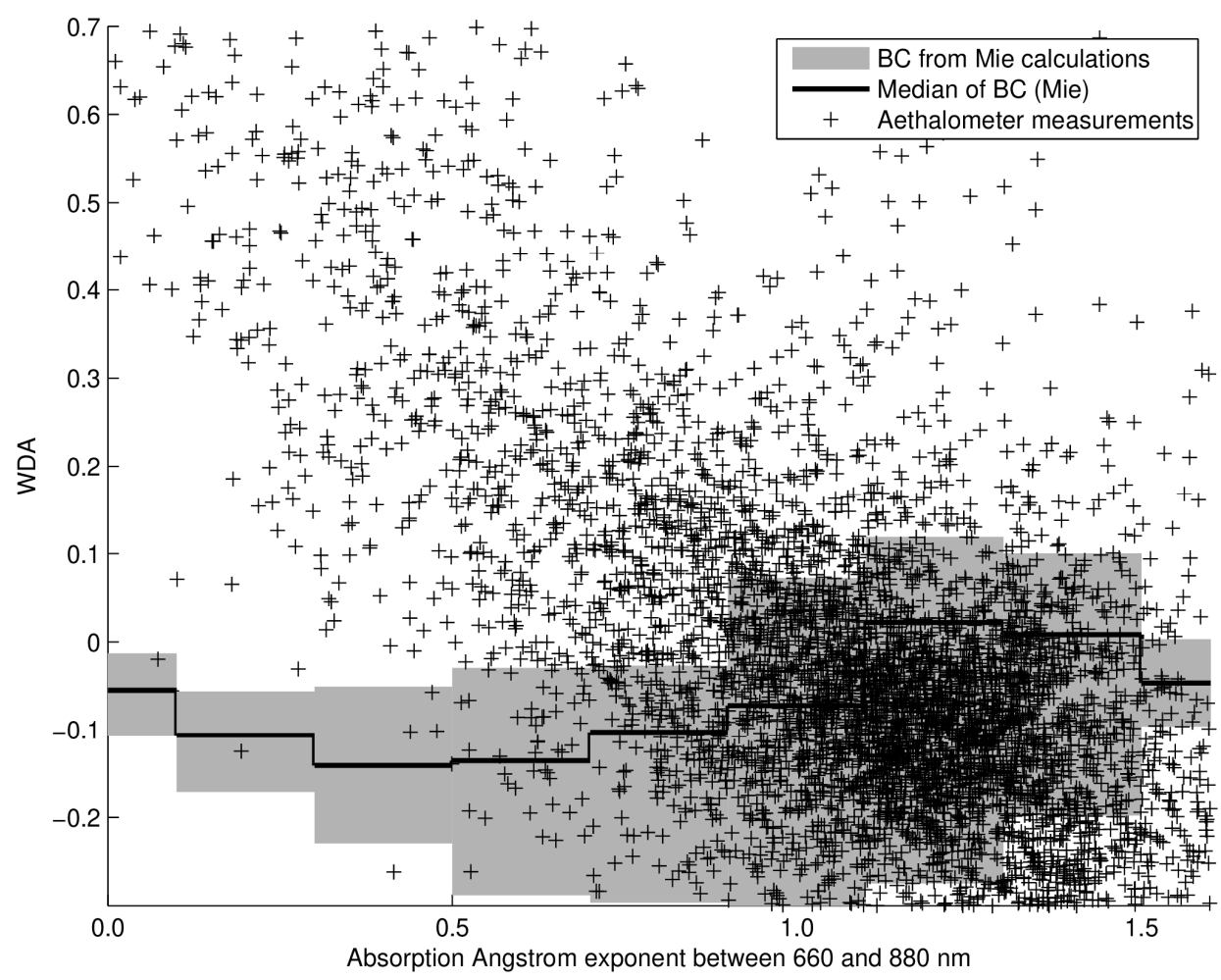

Fig. 4. WDA as a function of $\mathrm{AAE}_{660 / 880}$ for the Mie-calculated $\mathrm{BC}$ and aethalometer measurements. In the measurements above the shaded area, non-BC contribution to absorption coefficient is expected.

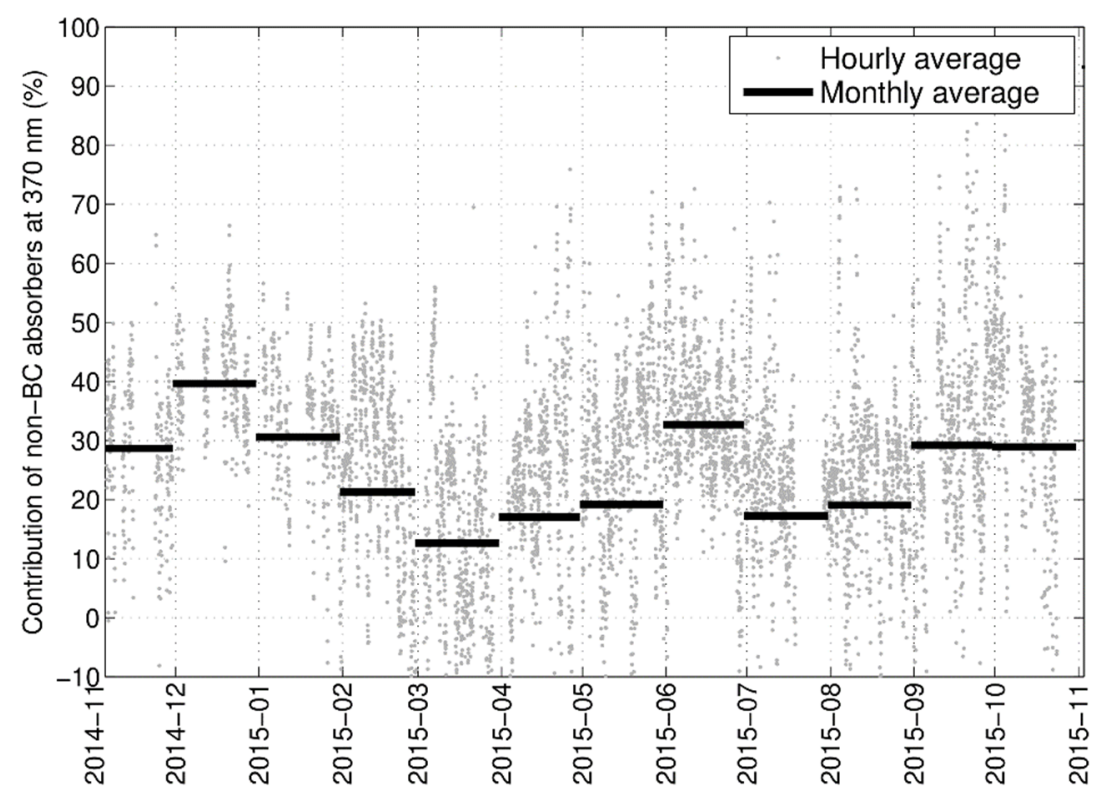

Fig. 5. The relative contribution of non-BC absorbers to the absorption coefficient at $370 \mathrm{~nm}$, obtained from the AE analysis, as a function of time, as hourly and monthly averages.

2015 ) to $43 \%$ (May 2015). The fraction of samples with non$\mathrm{BC}$ contribution was lower in winter and higher in spring, which reflect the higher and lower $\mathrm{BC}$ concentration and absorption coefficient at $880 \mathrm{~nm}$ in winter and spring, respectively (Figs. S5(a) and 2(a)). It must be noted that the number of valid samples for the WDA analysis was lower during the winter due to the gaps in the aethalometer data before mid-January 2015 (Fig. S13), which resulted in an overestimation of $3 \%$ in $\mathrm{BC}$ concentration as discussed earlier. This may also have an influence on the estimated non-BC contribution in winter. Unfortunately, due to missing AE data, a more detailed estimate for this influence is not possible.

In Fig. S14 the median non-BC contribution is given as a function of wind direction for different seasons and for the 
whole measurement period. This figure shows that there could be sources of non-BC absorbers, such as biomass burning, in the directions of northwest, where the median of the non$\mathrm{BC}$ contribution was $34.6 \%$ during the whole measurement period and $41.1 \%$ in winter, and in the direction of southeast with a $38.6 \%$ median non-BC contribution in winter.
Particles in the air masses originating from the continent (Sectors 4 and 5) contain more non-BC absorbers than those in the air masses originating from the marine sectors (Fig. 7). The highest non-BC contribution is in the particles originating from the northwestern sector (Sector 5). The probabilities of existence of non-BC absorbers in the samples from Sectors

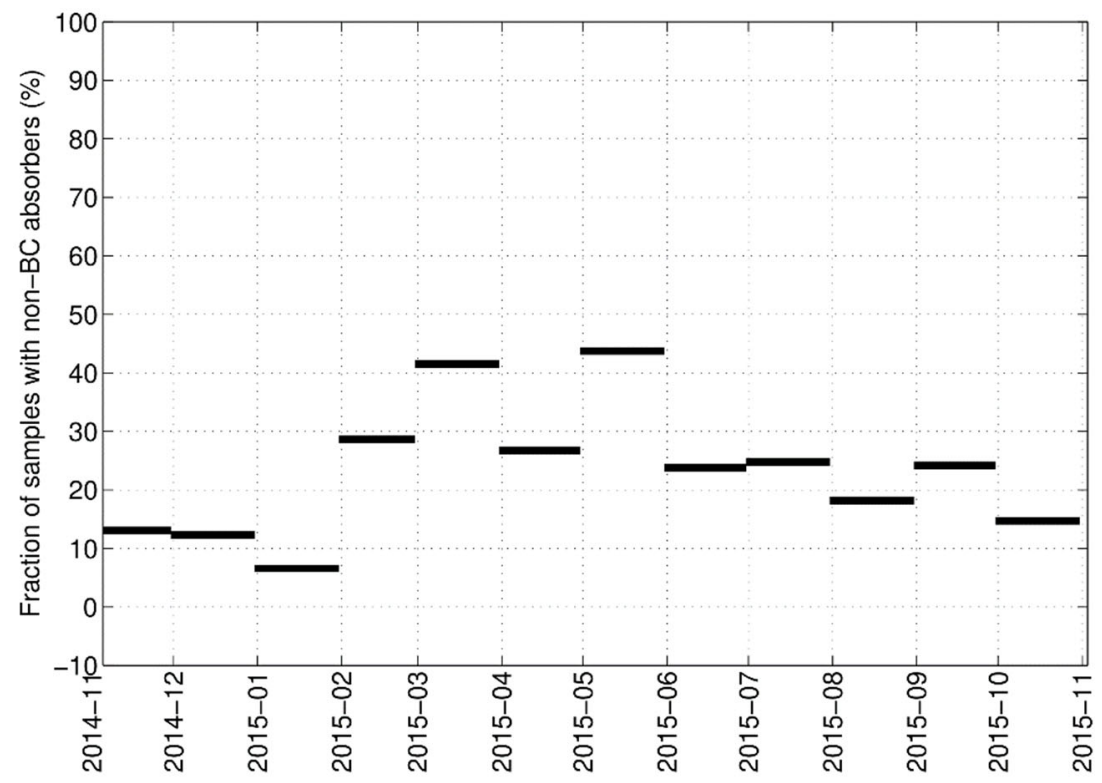

Fig. 6. Monthly distribution of the fraction of samples containing non-BC absorbers in addition to BC.
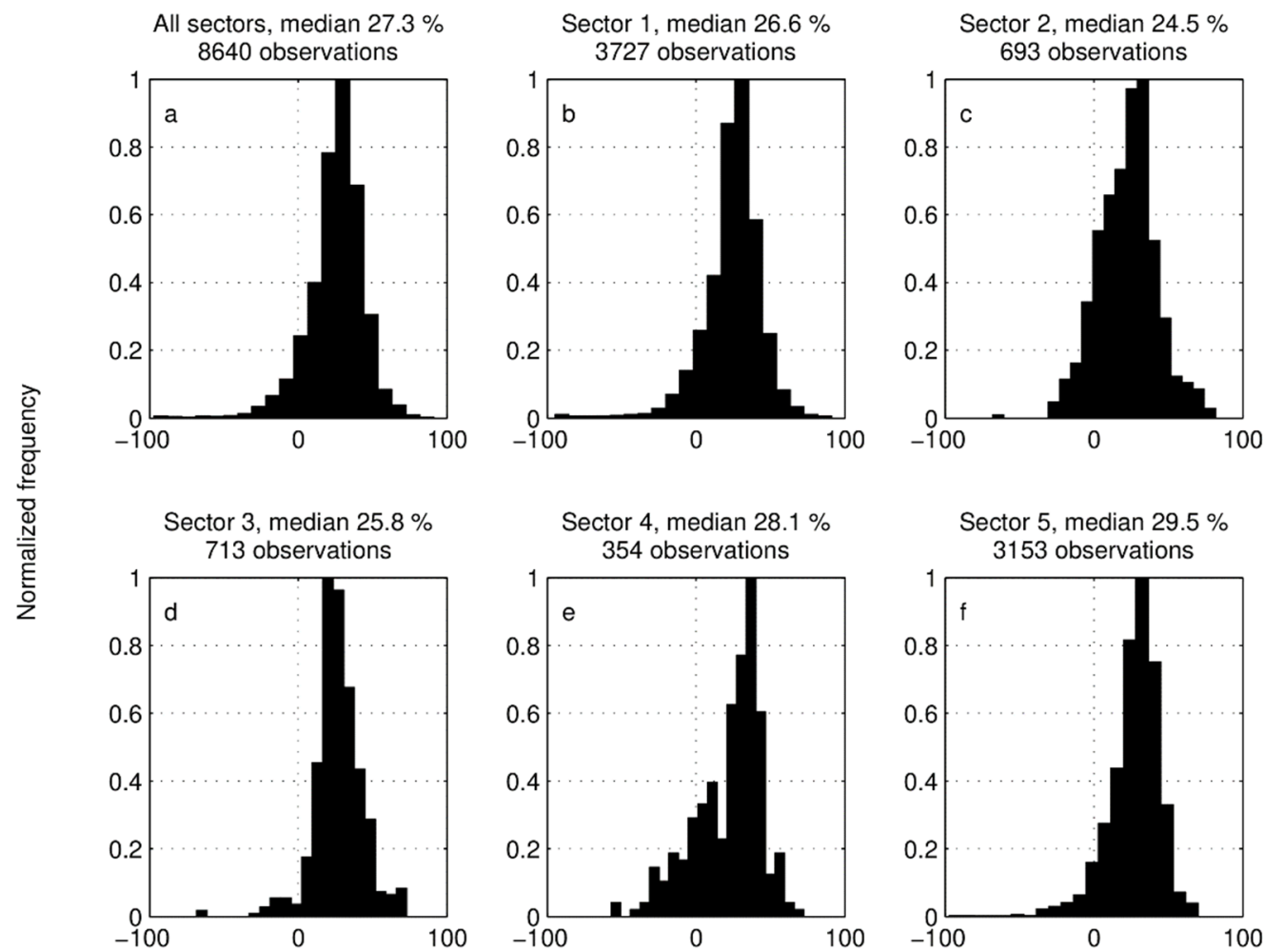

Relative non-BC contribution (\%)

Fig. 7. Frequency distribution of relative non-BC absorber contribution to absorption coefficient for (a) all trajectories and (b-f) Sectors 1-5. 
$1-5$ are $22.2 \%, 30.6 \%, 21.2 \%, 30.5 \%$, and $21.3 \%$, respectively This may be linked to the observations that the northwestern sector dominated during the wintertime (Fig. S3) and that elevated $\mathrm{BrC}$ concentrations in Xi'an, to the northwest of Nanjing, have been observed in winter (Huang et al., 2018). During the spring and summer months the air masses were mainly of maritime origin in the east and south directions (Fig. S15), which was also observed in Nanjing in 20132016 by Cheng et al. (2017).

It must be noted that our sector classification is based strictly on the highest fraction of the time spent in that sector (called "main sector") and that the air masses may also have spent almost as much time in another sector, as can be seen in the monthly distribution of the trajectories into different sectors (Fig. S15). This is true, in particular, for the trajectories which are near the sector borders. On average, the residence time in the main sector during the last 120 hours was 74 92 hours, i.e., $61.5-76.5 \%$ of the time. The shortest residence time, 74 hours, was for Sector 4, whose occurrence was also lowest, $4.1 \%$. For the other sectors, the occurrences and residence times were, respectively, $43.1 \%$ and 89 hours (Sector 1), 8.0\% and 76 hours (Sector 2), 8.3\% and 92 hours (Sector 3), and $36.5 \%$ and 82 hours (Sector 5). Our analysis relies on straightforward application of latitude and longitude of the backward trajectories, and some bias may arise from ignoring the air mass height and meteorological conditions along the trajectory. For example, a heavy rain can reduce the air pollutant concentrations remarkably, or intense solar irradiation may alter the properties of the aerosols in the air mass. During the local rain events during our campaign the $\mathrm{PM}_{10}$ and $\mathrm{PM}_{2.5}$ concentrations were observed to decrease. After the rain event the concentrations either increased back to the pre-rain level, or remained low. For the $\mathrm{BC}$ concentration and the contribution of non-BC absorbers to the absorption coefficient, the rain events had only a minor effect.

As each sector covers relatively big areas, it may be insufficient to apply local emission inventory to evaluate the source. In particular, the biomass burning from the northwestern sector (Sector 5) could be verified by a recent study (Yang and Zhao, 2019), which suggested intensive biomass burning emissions in northern provinces of Jiangsu and Anhui. Sector 5 was also the main sector in May-June and October-November (Fig. S3), the typical times for postharvest open biomass burning in eastern China (Cheng et al., 2014; Li et al., 2014).

\section{Source Area Analysis: Black Carbon and Non-BC Absorbers}

The minimum norm Tikhonov regularization method may mean that the actual absolute values for the source concentrations are not to be taken as "the truth," at least not before some sort of a validation is done. For this reason, only relative source concentrations are shown in Fig. 8 by normalizing the resulting source vectors $\mathrm{x}$. However, the
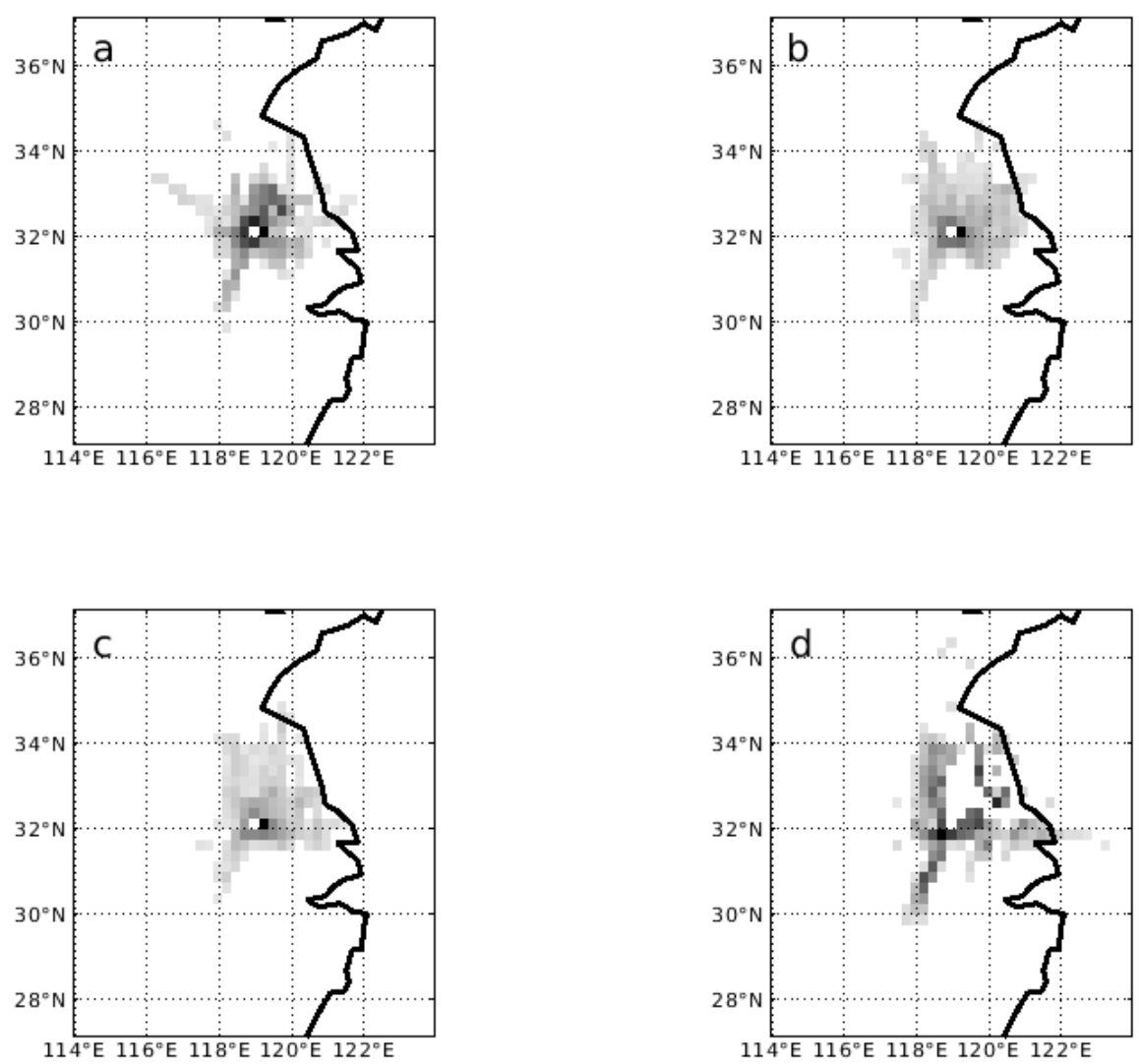

Fig. 8. The results of the source area analysis presented as source distribution maps: (a) high-BC sources, (b) high non-BC contribution, (c) low-BC sources, (d) low non-BC contribution. All maps have been normalized by maximum values for each case. Source concentration is indicated by darkness (darker color means a higher value). 
spatial distribution of the solution should be quite reliable. It must be noted that here the setting of the source area analysis differs considerably from the one presented in Hyvärinen et al. (2011) who exploited measurements from several measurement sites located around Finland instead of only one measurement site in this study. The lateral information in the back trajectories, i.e., the trajectory coordinates away from the strictly radial direction, becomes crucial when only one measurement site is available; otherwise only the direction of a source could be estimated, but not the distance of the source from the site.

To study the effect of $\mathrm{BC}$ and non-BC contribution, we divided the normalized values into two categories: "low" when the value was below the median $\left(3.0 \mu \mathrm{g} \mathrm{m}^{-3}\right.$ for $\mathrm{BC}$ concentration, 0.272 for non-BC contribution), and "high" when the value was equal or greater than the median. Fig. 8 (a) shows that the highest-BC sources reside in the vicinity of the measurement site and mostly in the northeast direction. Fig. 8(c), in turn, shows that the low-BC sources reside mainly in the sector between north and east of the measurement site, and thus the average $\mathrm{BC}$ concentration in these directions is lower than, e.g., in the south (Fig. S7). Shen et al. (2018) made a similar observation of lower BC concentration in the northeast direction from the nearby SORPES station, and they attributed this to a low photochemical age and thus a relatively close $\mathrm{BC}$ source, which supports our finding of the highest-BC sources in the same direction (Fig. 8(a)). There are also both high-BC sources and the highest end of low-BC sources in the south, which can also be seen as an elevated average $\mathrm{BC}$ concentration in this direction (Fig. S7). This may be attributed, at least partly, to emissions from the Nanjing city center, as was also observed by Shen et al. (2018).

The higher non-BC contribution (Fig. 8(b)) shows a similar pattern to the low-BC sources (Fig. 8(c)), indicating the abundance of non-BC absorbers in particles with less BC. The low-non-BC contribution pattern (Fig. 8(d)) is more scattered than the high-non-BC-contribution pattern (Fig. 8(c)), and it can be seen that the highest non-BC sources reside in the vicinity of the measurement site and in the southwest and northwest directions. The chemical analysis by Shen et al. (2018) revealed elevated scattering in west-northwest from the nearby SORPES station, and they suggested that aged biomass burning aerosol could be one factor for the elevated scattering. The non-BC contribution is, in turn, lower in the particles coming from a longer distance.

\section{CONCLUSIONS}

Based on both previous studies (e.g., Yang and Zhao, 2019) and the trajectory and source area analyses conducted in this study, we identify biomass burning emissions to the northwest of Nanjing as a source candidate for non-BC absorbers. The source area analysis also reveals that local emissions play a major role in both $\mathrm{BC}$ concentrations and non-BC absorber contributions, although particles arriving from farther away were also observed to exert an influence. Additionally, we agree with the conclusion drawn by
Miettinen et al. (2019), Zhao et al. (2017a), and Zhou et al. (2017) that the emission control measures implemented during the Nanjing Youth Olympic Games (YOG) in August 2014 improved the air quality in Nanjing. Combining our observations with those of Chen et al. (2017), we found that the elemental carbon (EC) concentrations were lower on average during August 2014 than during the same month in the preceding or the following year. Thus, although the improvement may have been temporary, the control measures produced a noticeable effect. Furthermore, the EC concentration trendline illustrated in this study suggests that the overall air quality in Nanjing has potentially improved in recent years.

\section{ACKNOWLEDGEMENTS}

The authors gratefully acknowledge the Academy of Finland (Grants 278331 and 278269) for funding the study and the NOAA Air Resources Laboratory (ARL) for the provision of the HYSPLIT transport and dispersion model and/or READY website (http://www.ready.noaa.gov) used in this publication.

\section{SUPPLEMENTARY MATERIAL}

Supplementary data associated with this article can be found in the online version at http://www.aaqr.org.

\section{REFERENCES}

Allen, R.J., Amiri-Farahani, A., Lamarque, J.F., Smith, C., Shindell, D., Hassan, T. and Chung, C.E. (2019). Observationally constrained aerosol-cloud semi-direct effects. npj Clim. Atmos. Sci. 2: 16.

Ammerlaan, B.A.J., Holzinger, R., Jedynska, A.D. and Henzing, J.S. (2017). Technical note: Aerosol light absorption measurements with a carbon analyser Calibration and precision estimates. Atmos. Environ. 164: $1-7$.

Arnott, W.P., Hamasha, K., Moosmuller, H., Sheridan, P.J. and Ogren, J.A. (2005). Towards aerosol light-absorption measurements with a 7-wavelength Aethalometer: Evaluation with a photoacoustic instrument and 3wavelength nephelometer. Aerosol Sci. Technol. 39: 1729.

Bohren, C.F. and Huffman, D.R. (1998). Absorption and scattering of light by small particles, Wiley-Interscience, New York.

Bond, T.C. and Bergström, R.W. (2006). Light absorption by carbonaceous particles: An investigative review. Aerosol Sci. Technol. 40: 27-67.

Bond, T.C., Doherty, S.J., Fahey, D.W., Forster, P.M., Berntsen, T., DeAngelo, B.J., Flanner, M. G., Ghan, S., Kärcher, B., Koch, D., Kinne, S., Kondo, Y., Quinn, P.K., Sarofim, M.C., Schultz, M.G., Schulz, M., Venkataraman, C., Zhang, H., Zhang, S., Bellouin, N., Guttikunda, S.K., Hopke, P.K., Jacobson, M.Z., Kaiser, J.W., Klimont, Z., Lohmann, U., Schwarz, J.P., Shindell, D., Storelvmo, T., Warren, S.G. and Zender, C.S. (2013). Bounding the role 
of black carbon in the climate system: A scientific assessment. J. Geophys. Res. 118: 5380-5552.

Brown, H., Liu, X., Feng, Y., Jiang, Y., Wu, M., Lu, Z., Wu, C., Murphy, S. and Pokhrel, R. (2018). Radiative effect and climate impacts of brown carbon with the Community Atmosphere Model (CAM5). Atmos. Chem. Phys. 18: 17745-17768.

Bukowiecki, N., Steinbacher, M., Henne, S., Nguyen, N.A., Nguyen, X.A., Hoang, A.L., Nguyen, D.L., Duong, H.L., Engling, G., Wehrle, G., Gysel-Beer, M. and Baltensperger, U. (2019). Effect of large-scale biomass burning on aerosol optical properties at the GAW regional station Pha Din, Vietnam. Aerosol Air Qual. Res. 19: 1172-1187.

Cappa, C.D., Onasch, T.B., Massoli, P., Worsnop, D.R., Bates, T.S., Cross, E.S., Davidovits, P., Hakala, J., Hayden, K.L., Jobson, B.T., Kolesar, K.R., Lack, D.A., Lerner, B.M., Li, S.M., Mellon, D., Nuaaman, I., Olfert, J.S., Petäjä, T., Quinn, P.K., Song, C., Subramanian, R., Williams, E.J. and Zaveri, R.A. (2012). Radiative absorption enhancements due to the mixing state of atmospheric black carbon. Science 337: 1078-1081.

Chen, D., Cui, H., Zhao, Y., Yin, L., Lu, Y. and Wang, Q. (2017). A two-year study of carbonaceous aerosols in ambient $\mathrm{PM}_{2.5}$ at a regional background site for western Yangtze River Delta, China. Atmos. Res. 183: 351-361.

Cheng, F., Zha, Y., Zhang, J., He, J. and Yan, S. (2017). A study on distance transport of $\mathrm{PM}_{2.5}$ to Xianlin in Nanjing, China and its source areas. Aerosol Air Qual. Res. 17: 1672-1683.

Cheng, Y., He, K.B., Zheng, M., Duan, F.K., Du, Z.Y., Ma, Y.L., Tan, J.H., Yang, F.M., Liu, J.M., Zhang, X.L., Weber, R.J., Bergin, M.H. and Russell, A.G. (2011). Mass absorption efficiency of elemental carbon and water-soluble organic carbon in Beijing, China. Atmos. Chem. Phys. 11: 11497-11510.

Cheng, Z., Wang, S., Fu, X., Watson, J.G., Jiang, J., Fu, Q., Chen, C., Xu, B., Yu, J., Chow, J.C. and Hao, J. (2014). Impact of biomass burning on haze pollution in the Yangtze River delta, China: a case study in summer 2011. Atmos. Chem. Phys. 14: 4573-4585.

Clarke, A.D., Shinozuka, Y., Kapustin, V.N., Howell, S., Huebert, B., Doherty, S., Anderson, T., Covert, D., Anderson, J., Hua, X., Moore, K.G. II, McNaughton, C., Carmichael, G. and Weber, R. (2004). Size distributions and mixtures of dust and black carbon aerosol in Asian outflow: Physiochemistry and optical properties. $J$. Geophys. Res. 109: D15S09.

Collaud Coen, M., Weingartner, E., Apituley, A., Ceburnis, D., Fierz-Schmidhauser, R., Flentje, H., Henzing, J.S., Jennings, S.G., Moerman, M., Petzold, A., Schmid, O. and Baltensperger, U. (2010). Minimizing light absorption measurement artifacts of the Aethalometer: Evaluation of five correction algorithms. Atmos. Meas. Tech. 3: 457474.

Ding, A.J., Fu, C.B., Yang, X.Q., Sun, J.N., Zheng, L.F., Xie, Y.N., Herrmann, E., Nie, W., Petäjä, T., Kerminen, V.M. and Kulmala, M. (2013). Ozone and fine particle in the western Yangtze River Delta: an overview of 1 yr data at the SORPES station. Atmos. Chem. Phys. 13: 5813-
5830.

Drinovec, L., Močnik, G., Zotter, P., Prévôt, A.S.H., Ruckstuhl, C., Coz, E., Rupakheti, M., Sciare, J., Müller, T., Wiedensohler, A. and Hansen, A.D.A. (2015). The "dual-spot" Aethalometer: an improved measurement of aerosol black carbon with real-time loading compensation. Atmos. Meas. Tech. 8: 1965-1979.

Hadley, O.L. and Kirchstetter, T.W. (2012). Black-carbon reduction of snow albedo. Nat. Clim. Change 2: 437-440.

Hansen, A.D.A., Rosen, H. and Novakov, T. (1984). The aethalometer - an instrument for the real-time measurement of optical absorption by aerosol particles. Sci. Total Environ. 36: 191-196.

Huang, R.J., Yang, L., Cao, J., Chen, Y., Chen, Q., Li, Y., Duan, J., Zhu, C., Dai, W., Wang, K., Lin, C., Ni, H., Corbin, J.C., Wu, Y., Zhang, R., Tie, X., Hoffmann, T., O'Dowd, C. and Dusek, U. (2018). Brown carbon aerosol in urban Xi'an, northwest China: The composition and light absorption properties. Environ. Sci. Technol. 52: 6825-6833.

Hyvärinen, A.P., Kolmonen, P., Kerminen, V.M., Virkkula, A., Leskinen, A., Komppula, M., Hatakka, J., Burkhart, J., Stohl, A., Aalto, P., Kulmala, M., Lehtinen, K.E.J., Viisanen, Y. and Lihavainen, H. (2011). Aerosol black carbon at five background measurement sites over Finland, a gateway to the Arctic. Atmos. Environ. 45: 4042-4050.

Janssen, N.A.H., Gerlofs-Nijland, M.E., Lanki, T., Salonen, R.O., Cassee, F., Hoek, G., Fischer, P., Brunekreef, B., and Krzyzanowski, M. (2012). In Health effects of black carbon (Bohr R., Ed.), World Health Organization.

Kim, J.H., Kim, S.W., Ogren, J.A., Sheridan, P.J., Yoon, S.C., Sharma, S. and Lin, N.H. (2018). Multiple scattering correction factor estimation for aethalometer aerosol absorption coefficient measurement. Aerosol Sci. Technol. 53: $160-171$.

Kirchstetter, T.W. and Thatcher, T.L. (2012). Contribution of organic carbon to wood smoke particulate matter absorption of solar radiation. Atmos. Chem. Phys. 12: 6067-6072.

Lack, D.A. and Langridge, J.M. (2013). On the attribution of black and brown carbon light absorption using the Ångström exponent. Atmos. Chem. Phys. 13: 1053510543.

Li, J., Song, Y., Mao, Y., Mao, Z., Wu, Y., Li, M., Huang, X., He, Q. and Hu, M. (2014). Chemical characteristics and source apportionment of $\mathrm{PM}_{2.5}$ during the harvest season in eastern China's agricultural regions. Atmos. Environ. 92: 442-448.

Liu, C., Chung, C.E., Yin, Y. and Schnaiter, M. (2018). The absorption Ångström exponent of black carbon: from numerical aspects. Atmos. Chem. Phys. 18: 6259-6273.

Miettinen, M., Leskinen, A., Abbaszade, G., Orasche, J., Sainio, M., Mikkonen, S., Koponen, H., Rönkkö, T., Ruusunen, J., Kuuspalo, K., Tiitta, P., Jalava, P., Hao, L., Fang, D., Wang, Q., Gu, C., Zhao, Y., Michalke, B., Schnelle-Kreis, J., Lehtinen, K.E.J., Zimmermann, R., Komppula, M., Jokiniemi, J., Hirvonen, M.R. and Sippula, O. (2019). $\mathrm{PM}_{2.5}$ concentration and composition in the 
urban air of Nanjing, China: Effects of emission control measures applied during the 2014 Youth Olympic Games. Sci. Total Environ. 652: 1-18.

Müller, T., Henzing, J.S., de Leeuw, G., Wiedensohler, A., Alastuey, A., Angelov, H., Bizjak, M., Collaud Coen, M., Engström, J.E., Gruening, C., Hillamo, R., Hoffer, A., Imre, K., Ivanow, P., Jennings, G., Sun, J.Y., Kalivitis, N., Karlsson, H., Komppula, M., Laj, P., Li, S.M., Lunder, C., Marinoni, A., Martins dos Santos, S., Moerman, M., Nowak, A., Ogren, J.A., Petzold, A., Pichon, J.M., Rodriquez, S., Sharma, S., Sheridan, P.J., Teinilä, K., Tuch, T., Viana, M., Virkkula, A., Weingartner, E., Wilhelm, R. and Wang, Y.Q. (2011). Characterization and intercomparison of aerosol absorption photometers: result of two intercomparison workshops. Atmos. Meas. Tech. 4: 245-268.

Petzold, A. and Schönlinner, M. (2004). Multi-angle absorption photometry - A new method for the measurement of aerosol light absorption and atmospheric black carbon. J. Aerosol Sci. 35: 421-441.

Petzold, A., Schloesser, H., Sheridan, P.J., Arnott, W.P., Ogren, J.A. and Virkkula, A. (2005). Evaluation of multiangle absorption photometry for measuring aerosol light absorption. Aerosol Sci. Technol. 39: 40-51.

Petzold, A., Ogren, J.A., Fiebig, M., Laj, P., Li, S.M., Baltensperger, U., Holzer-Popp, T., Kinne, S., Pappalardo, G., Sugimoto, N., Wehrli, C., Wiedensohler, A. and Zhang, X.Y. (2013). Recommendations for reporting "black carbon" measurements. Atmos. Chem. Phys. 13: 8365-8379.

Quinn, P.K. and Bates, T.S. (2005). Regional aerosol properties: Comparisons of boundary layer measurements from ACE 1, ACE 2, Aerosols99, INDOEX, ACE Asia, TARFOX, and NEAQS. J. Geophys. Res. 110: D14202.

Ran, L., Deng, Z.Z., Wang, P.C. and Xia, X.A. (2016). Black carbon and wavelength-dependent aerosol absorption in the North China Plain based on two-year aethalometer measurements. Atmos. Environ. 142: 132-144.

Rolph, G., Stein, A. and Stunder, B. (2017). Real-time Environmental Applications and Display sYstem: READY. Environ. Modell. Software 95: 210-228.

Saturno, J., Holanda, B.A., Pöhlker, C., Ditas, F., Wang, Q., Moran-Zuloaga, D., Brito, J., Carbone, S., Cheng, Y., Chi, X., Ditas, J., Hoffmann, T., Hrabe de Angelis, I., Könemann, T., Lavrič, J.V., Ma, N., Ming, J., Paulsen, H., Pöhlker, M.L., Rizzo, L.V., Schlag, P., Su, H., Walter, D., Wolff, S., Zhang, Y., Artaxo, P., Pöschl, U. and Andreae, M.O. (2018). Black and brown carbon over central Amazonia: Long-term aerosol measurements at the ATTO site. Atmos. Chem. Phys. 18: 12817-12843.

Schäfer, J.P. (2011). In Implementierung und Anwendung analytischer und numerischer Verfahren zur Lösung der Maxwellgleichungen für die Untersuchung der Lichtausbreitung in biologischem Gewebe, Universität Ulm, Germany.

Schäfer, J., Lee, S.C. and Kienle, A. (2012). Calculation of the near fields for the scattering of electromagnetic waves by multiple infinite cylinders at perpendicular incidence. J. Quant. Spectrosc. Radiat. Trans. 113: 2113-2123.
Schmid, O., Artaxo, P., Arnott, W.P., Chand, D., Gatti, L.V., Frank, G.P., Hoffer, A., Schnaiter, M. and Andreae, M.O. (2006). Spectral light absorption by ambient aerosols influenced by biomass burning in the Amazon Basin. I: Comparison and field calibration of absorption measurement techniques. Atmos. Chem. Phys. 6: 34433462.

Shen, Y., Virkkula, A., Ding, A., Wang, J., Chi, X., Nie, W., Qi, X., Huang, X., Liu, Q., Zheng, L., Xu, Z., Petäjä, T., Aalto, P.P., Fu, C. and Kulmala, M. (2018). Aerosol optical properties at SORPES in Nanjing, East China. Atmos. Chem. Phys. 18: 5265-5292.

Stein, A.F., Draxler, R.R., Rolph, G.D., Stunder, B.J.B., Cohen, M.D. and Ngan, F. (2015). NOAA's HYSPLIT atmospheric transport and dispersion modeling system. Bull. Am. Meteorol. Soc. 96: 2059-2077.

Tarantola, A. (1987). Inverse Problem theory. Elsevier Science, Amsterdam, The Netherlands.

Virkkula, A., Chi, X., Ding, A., Shen, Y., Nie, W., Qi, X., Zheng, L., Huang, X., Xie, Y., Wang, J., Petäjä, T. and Kulmala, M. (2015). On the interpretation of the loading correction of the aethalometer. Atmos. Meas. Tech. 8: 4415-4427.

Virkkula, A., Mäkelä, T., Hillamo, R., Yli-Tuomi, T., Hirsikko, A., Hämeri, K. and Koponen, I.K. (2007). A simple procedure for correcting loading effects of aethalometer data. J. Air Waste Manage. Assoc. 57: 12141222.

Wang, X., Heald, C.L., Sedlacek, A.J., de Sá, S.S., Martin, S.T., Alexander, M.L., Watson, T.B., Aiken, A.C., Springston, S.R. and Artaxo, P. (2016). Deriving brown carbon from multiwavelength absorption measurements: method and application to AERONET and Aethalometer observations. Atmos. Chem. Phys. 16: 12733-12752.

Washenfelder, R.A., Attwood, A.R., Brock, C.A., Guo, H., Xu, L., Weber, R.J., Ng, N.L., Allen, H.M., Ayres, B.R., Baumann, K., Cohen, R.C., Draper, D.C., Duffey, K.C., Edgerton, E., Fry, J.L., Hu, W.W., Jimenez, J.L., Palm, B.B., Romer, P., Stone, E.A., Wooldridge, P.J. and Brown, S.S. (2015). Biomass burning dominates brown carbon absorption in the rural southeastern United States. Geophys. Res. Lett. 42: 653-664.

Weingartner, E., Saathoff, H., Schnaiter, M., Streit, N., Bitnar, B. and Baltensperger, U. (2003). Absorption of light by soot particles: Determination of the absorption coefficient by means of aethalometers. J. Aerosol Sci. 34: 1445-1463.

Yang, Y. and Zhao, Y. (2019). Quantification and evaluation of atmospheric pollutant emissions from open biomass burning with multiple methods: A case study for Yangtze River Delta region, China. Atmos. Chem. Phys. 19: 327348.

Zhang, G., Bi, X., Qiu, N., Han, B., Lin, Q., Peng, L., Chen, D., Wang, X., Peng, P., Sheng, G. and Zhou, Z. (2016). The real part of the refractive indices and effective densities for chemically segregated ambient aerosols in Guangzhou measured by a single-particle aerosol mass spectrometer. Atmos. Chem. Phys. 16: 2631-2640.

Zhang, G., Peng, L., Lian, X., Lin, Q., Bi, X., Chen, D., Li, 
M., Li, L., Wang, X. and Sheng, G. (2018a). An improved absorption Ångström exponent (AAE)-based method for evaluating the contribution of light absorption from brown carbon with a high-time resolution. Aerosol Air Qual. Res. 19: 15-24.

Zhang, Q., Shen, Z., Lei, Y., Wang, Y., Zeng, Y., Wang, Q., Ning, Z., Cao, J., Wang, L. and Xu, H. (2018b). Variations of particle size distribution, black carbon, and brown carbon during a severe winter pollution event over Xi'an, China. Aerosol Air Qual. Res. 18: 1419-1430.

Zhang, Y., Li, Z., Zhang, Y., Li, D., Qie, L., Che, H. and Xu, H. (2017). Estimation of aerosol complex refractive indices for both fine and coarse modes simultaneously based on AERONET remote sensing products. Atmos. Meas. Tech. 10: 3203-3213.

Zhao, H., Zheng, Y. and Li, T. (2017a). Air quality and control measures evaluation during the 2014 Youth Olympic Games in Nanjing and its surrounding cities. Atmosphere 8: 100.

Zhao, Q., Shen, G., Li, L., Chen, F., Qiao, Y., Li, C., Liu, Q. and Han, J. (2017b). Ambient particles $\left(\mathrm{PM}_{10}, \mathrm{PM}_{2.5}\right.$ and $\mathrm{PM}_{1.0}$ ) and $\mathrm{PM}_{2.5}$ chemical components in Western Yangtze River Delta (YRD): An overview of data from 1year online continuous monitoring at Nanjing. Aerosol Sci. Eng. 1: 107-118.

Zhi, G., Chen, Y., Xue, Z., Meng, F., Cai, J., Sheng, G. and
Fu, J. (2014). Comparison of elemental and black carbon measurements during normal and heavy haze periods: Implications for research. Environ. Monit. Assess. 186: 6097-6106.

Zhou, D., Li, B., Huang, X., Virkkula, A., Wu, H., Zhao, Q., Zhang, J., Liu, Q., Li, L., Li, C., Chen, F., Yuan, S., Qiao, Y., Shen, G. and Ding, A. (2017). The impacts of emission control and regional transport on $\mathrm{PM}_{2.5}$ ions and carbon components in Nanjing during the 2014 Nanjing Youth Olympic Games. Aerosol Air Qual. Res. 17: 730740.

Zhuang, B.L., Wang, T.J., Liu, J., Li, S., Xie, M., Yang, X.Q., Fu, C.B., Sun, J.N., Yin, C.Q., Liao, J.B., Zhu, J.L. and Zhang, Y. (2014). Continuous measurement of black carbon aerosol in urban Nanjing of Yangtze River Delta, China. Atmos. Environ. 89: 415-424.

Zhuang, B.L., Wang, T.J., Liu, J., Li, S., Xie, M., Han, Y., Chen, P., Hu, Q., Yang, X.Q., Fu, C. and Zhu, J. (2017). The surface aerosol optical properties in the urban area of Nanjing, west Yangtze River Delta, China. Atmos. Chem. Phys. 17: 1143-1160.

Received for review, June 27, 2019

Revised, January 17, 2020

Accepted, February 1, 2020 